\title{
USED FUEL RAIL SHOCK AND VIBRATION TESTING OPTIONS ANALYSIS
}

\section{Fuel Cycle Research \& Development}

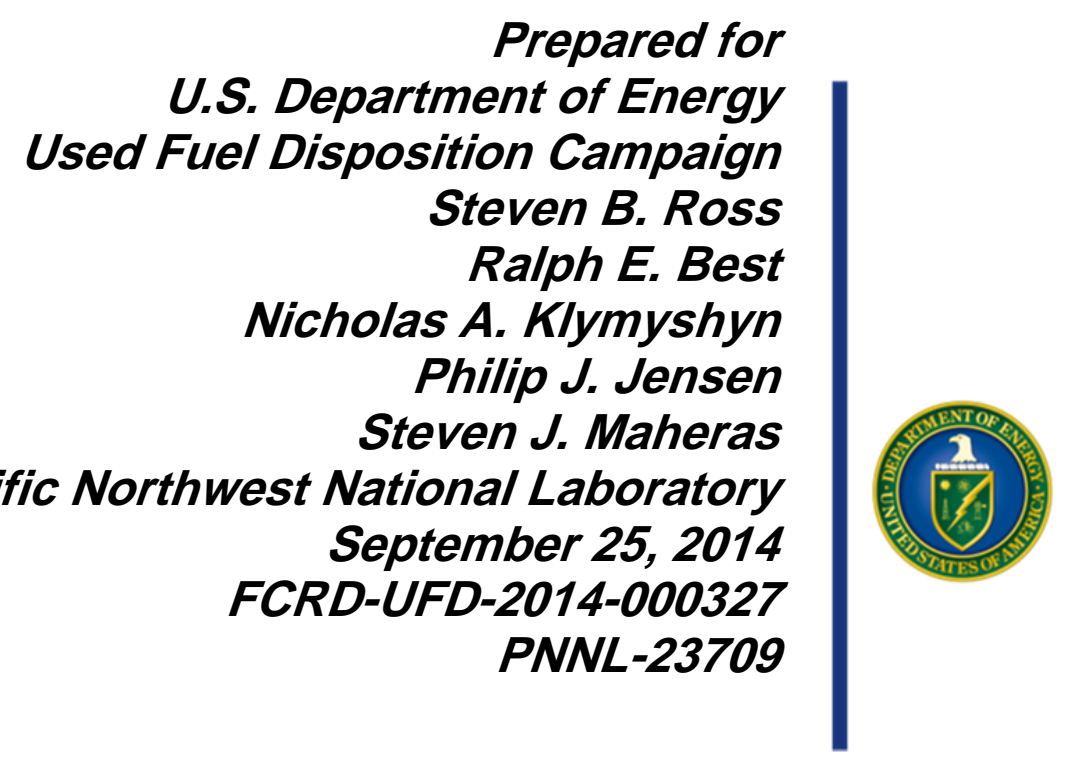




\section{DISCLAIMER}

This information was prepared as an account of work sponsored by an agency of the U.S. Government. Neither the U.S. Government nor any agency thereof, nor any of their employees, makes any warranty, expressed or implied, or assumes any legal liability or responsibility for the accuracy, completeness, or usefulness, of any information, apparatus, product, or process disclosed, or represents that its use would not infringe privately owned rights. References herein to any specific commercial product, process, or service by trade name, trade mark, manufacturer, or otherwise, does not necessarily constitute or imply its endorsement, 
Used Fuel Rail Shock and Vibration Testing Options Analysis

September 25, 2014

i

Reviewed by:

PNNL Project Manager

Signature on file

$9 / 29 / 2014$

Brady Hanson

Date 


\section{EXECUTIVE SUMMARY}

This report fulfills the requirements for milestone M3FT-14PN0813032 "Fuel Assembly Test Plan” under work package FT-14PN081303.

The objective of the rail shock and vibration tests is to complete the framework needed to quantify loads of fuel assembly components that are necessary to guide materials research and establish a technical basis for review organizations such as the U.S. Nuclear Regulatory Commission (NRC). A significant body of experimental and numerical modeling data exists to quantify loads and failure limits applicable to normal conditions of transport (NCT) rail transport, but the data are based on assumptions that can only be verified through experimental testing. The test options presented in this report represent possible paths for acquiring the data that are needed to confirm the assumptions of previous work, validate modeling methods that will be needed for evaluating transported fuel on a case-by-case basis, and inform material test campaigns on the anticipated range of fuel loading. The ultimate goal of this testing is to close all of the existing knowledge gaps related to the loading of used fuel under NCT conditions and inform the experiments and analysis program on specific endpoints for their research.

The U.S. Department of Energy Office of Nuclear Energy (DOE-NE), Office of Fuel Cycle Technology, established the Used Fuel Disposition Campaign (UFDC) to conduct the research and development activities related to storage, transportation, and disposal of used nuclear fuel and high-level radioactive waste. The mission of the UFDC is to identify alternatives and conduct scientific research and technology development to enable storage, transportation, and disposal of used nuclear fuel (UNF) and wastes generated by existing and future nuclear fuel cycles. The Storage and Transportation staff within the UFDC are responsible for addressing issues regarding the extended or long-term storage of UNF and its subsequent transportation. Until a disposition pathway, e.g., recycling or geologic disposal, is chosen and implemented, the storage periods for UNF will likely be longer than were originally intended.

The ability of the important-to-safety structures, systems, and components (SSCs) to continue to meet safety functions over extended times must be determined and demonstrated. In addition, the ability of these SSCs to meet applicable safety functions when the UNF is transported must be ensured. To facilitate all options for disposition and to maintain retrievability and normal backend operations, an important objective of this program is to evaluate the likelihood that the UNF remains undamaged after extended storage. This does not preclude consideration of other options - such as canning of all UNF - from a total systems perspective to determine overall benefit to nuclear waste management.

As discussed in a report on used fuel performance characterization (Adkins et al. 2013a) under NRC regulations, it is not sufficient for UNF to simply maintain its integrity during the storage period. It must maintain its integrity in such a way that it can withstand the physical forces of handling and transportation associated with restaging the fuel and moving it to a different location (such as an interim storage site, a geologic repository, or a treatment/recycling facility). Hence, understanding mechanical performance under cumulative loading stemming from normal conditions of storage (NCS), transfer (from storage container to transport container if needed), and NCT is necessary as it establishes part of the safety basis by maintaining the fuel-confining 
boundary (geometry) and criticality safety, and is one of the critical components to the preservation of retrievability. Because of this, an important part of UFDC research and development is related to the mechanical loads on used nuclear fuel, cladding, and key structural components of the fuel assembly during NCT and NCS, and the response of the used fuel and assembly to those loads.

Available information is not sufficient to determine the ability of high-burnup or long-cooled used nuclear fuel to withstand shock and vibration forces that could occur when the UNF is shipped by rail from nuclear power plant sites to a storage or disposal facility. There are three major gaps in the available information: the forces that UNF assemblies would be subjected to when transported by rail; the mechanical characteristics of fuel rod cladding, which is an essential structure for controlling the geometry of the UNF, a safety-related feature; and modeling methodologies to evaluate multiple possible degradation or damage mechanisms over the UNF lifetime. This report discusses testing options that are designed to significantly increase available information regarding the forces that UNF assemblies would be subjected to during normal rail transportation. Other research being conducted by the UFDC is designed to increase available information regarding the mechanical characteristics of the fuel rod cladding potential shock and vibration loads, and the finite element modeling of the used fuel behavior.

A straightforward approach to resolve the need for additional information would be to conduct physical tests where a representative sample of high-burnup UNF assemblies would be subjected to rail transportation shock and vibration in the course of real rail shipments. The results would be determined by direct examination-do the assemblies survive or do they fail? This approach is not feasible for several reasons: cost, radiological safety of workers and of the public, unlikely participation by a railroad or railroads, and the incompleteness of the information that would be collected, to name a few.

Therefore, this report identifies and evaluates options for tests to determine the physical response of surrogate used fuel assemblies subjected to shock and vibration forces that would be experienced during normal conditions of rail transportation in a cask (or surrogate cask) transported on a railcar. This is a follow-on effort related to the recent tests conducted by Sandia National Laboratories to measure the response of a surrogate nuclear fuel assembly to shock and vibration that would occur during normal highway transport by truck (McConnell et al. 2014).

The options include tests that would use an actual railcar, surrogate assemblies, and real or simulated rail transportation casks. The railcar carrying the cradle, cask, and surrogate fuel assembly payload would be moved in a train operating over rail track modified or selected to impart shock and vibration forces that occur during normal rail transportation. Computer modeling would be used to help design surrogates that may be needed for a rail cask, a cask's internal basket, and a transport cradle. The objective of the design of surrogate components would be to provide a test platform that effectively simulates responses to rail shock and vibration loads that would be exhibited by state-of-the-art rail cask, basket, and/or cradle structures. The computer models would also be used to help determine the placement of instrumentation (accelerometers and strain gauges) on the surrogate fuel assemblies, cask and cradle structures, and the railcar so that forces and deflections that would result in the greatest potential for damage to high burnup and long-cooled UNF can be determined. For purposes of 
this report we consider testing on controlled track when we have control of the track and speed to facilitate modeling. Tables ES-1 through ES-4 present the advantages and disadvantages of the shock and vibration testing options described in this report.

Section 1 of this report introduces rail transportation shock and vibration testing as it relates to other research being conducted by the UFDC. Section 2 describes the objectives for conducting rail shock and vibration tests. Section 3 discusses four options for rail shock and vibration testing to meet the objectives. Section 4 describes the analysis of the testing options. Section 5 describes the elements of the shock and vibration testing including the testing environment and instrumentation. Section 6 presents a summary of the options analysis.

Table ES-1. Summary of Option 1, TN-32 (Tri-City Railroad)

\begin{tabular}{|c|c|}
\hline \multicolumn{2}{|c|}{ Option 1 Highlights } \\
\hline $\begin{array}{ll}\text { - } & \text { S\&V testing in a controlled environment with a T } \\
\text { - } & \text { Washington } \\
\text { - } & \text { deck railcar or depressed-center railcar } \\
\text { - } & \text { Potential for cross-county travel S\&V data collec }\end{array}$ & 2 "sister" cask at the TCRY facilities in Richland, \\
\hline Advantages & Disadvantages \\
\hline $\begin{array}{l}\text { Technical } \\
\text { - } \quad \text { TCRY testing capability, flexibility, access, and } \\
\text { convenience } \\
\text { - } \quad \text { TN-32 is modern storage cask } \\
\text { - } \quad \text { AREVA-designed transport cradle and basket } \\
\text { - } \quad \text { Flexibility in railcar selection } \\
\text { - } \quad \text { entrolled test environment correlates to finite } \\
\text { - TCRY access to revenue track, if desired } \\
\text { Cross-country trip representative of routing for } \\
\text { UNF shipments }\end{array}$ & $\begin{array}{l}\text { Technical } \\
\text { - } \quad \text { Modeling used to simulate impact limiters } \\
\text { - } \quad \text { S\&V data collected for long distance traveled lack a } \\
\text { controlled environment, which makes correlation to } \\
\text { finite element modeling difficult. } \\
\text { - } \quad \text { Data collection system chance for failure en route } \\
\text { Cost } \\
\text { - } \quad \text { Lease or purchase TN-32 cask } \\
\text { - Cost for use of basket or for AREVA to fabricate } \\
\text { - } \quad \text { Cosket and cradle } \\
\text { - Pennsylvania to Richland, Washington } \\
\text { Cost, viability, and access to instrumentation and } \\
\text { data collection system and monitoring for potential } \\
\text { cross-country data collection (if used) } \\
\text { Cost and complexity to provide special cask lid or } \\
\text { other arrangements to allow fuel assembly and basket } \\
\text { instrumentation to pass through to outside of cask }\end{array}$ \\
\hline
\end{tabular}


Table ES-2. Summary of Option 2, TN-32 (Dominion)

\section{Option 2 Highlights}

- $\quad \mathrm{S} \& V$ testing with a TN-32 cask in transit from Precision Components Corporation Facility (York, Pennsylvania) to Columbiana High Tech in Greensboro, North Carolina

- $\quad$ SNL and AREVA assemblies

- $\quad$ Flat deck railcar or depressed-center railcar

\begin{tabular}{|c|l|}
\hline \multicolumn{1}{|c|}{ Advantages } & \multicolumn{1}{c}{ Disadvantages } \\
\hline Technical & Technical
\end{tabular}

- $\quad$ TN-32 cask is a modern storage/transport cask that will be used to transport HBU fuel following the dry storage tests at the North Anna nuclear power plant

- Cost of TN-32 cask paid for by Dry Storage Demonstration Project

- AREVA instrumented 17X17 surrogate assemblies (for North Anna fuel assemblies)

- Collaboration with industry and utilities

- Fabrication of basket and cradle by AREVA

- $\mathrm{S} \& V$ data collected during long-distance commercial rail transport

- Acquisition of railcar by AREVA

- Cost

- Cost of proposed rail trip from Pennsylvania to North Carolina paid for by Dry Storage Demonstration Project
- Logistics, complexity, and time required to set up and coordinate the scope and details of testing before, and not to interfere with, start of the Dominion dry storage demonstration tests

- Modeling used to simulate impact limiters

- $\mathrm{S} \& \mathrm{~V}$ data collected for long distance traveled lack a controlled environment, which makes correlation to finite element modeling difficult.

- Data collection system chance for failure enroute

- Sources of S\&V forces occurring enroute not practically verifiable

- Limited rail travel not representative of routing for UNF shipment

- $\mathrm{S} \& V$ input forces for rail route traveled cannot be determined to be representative of the range of forces that would occur for travel on all routes that could be used to ship HBU UNF unless extensive rail travel is undertaken

- Potential that it will not be possible to instrument basket that will be used in North Anna dry storage tests

- Less flexibility in selection of railcar

Cost

- Cost for use of basket or for AREVA to fabricate basket and cradle

- Complexity of instrumenting fuel assemblies inside cask without special closure lid or cost of special lid arrangement

HBU = high burnup, S\&V = shock and vibration, SNL = Sandia National Laboratories, UNF = used nuclear fuel 
Table ES-3. Summary of Option 3, NLI 10/24

\section{Option 3 Highlights}

- S\&V testing in a controlled environment with a NLI-10/24 cask at TCRY facility in Richland, Washington

- Potential for data collection cross country from Augusta, Georgia to TCRY in Richland, Washington

- $\quad$ SNL and AREVA assemblies

- $\quad$ NLIX flat deck railcar

- Potential for cross-county travel S\&V data collection with basket and surrogate assemblies

\begin{tabular}{|l|l|}
\hline \multicolumn{1}{|c|}{ Advantages } & \multicolumn{1}{c|}{ Disadvantages } \\
\hline Technical & Technical
\end{tabular}

- TCRY owns the NLI cask and railcar, which will be domiciled at the TCRY Richland, Washington facility.

- Ability to perform controlled repeatable experiments over known track conditions at TCRY to better inform modeling

- $\quad$ NLIX railcar specifically designed for the NLI cask

- $\quad$ NLI cask is a previously certified 100-ton UNF rail transportation cask

- Controlled test environment correlates to finite element modeling

- $\quad$ TCRY access to revenue track, if desired

- Cross-country trip representative of routing for UNF shipments

\section{Cost}

- Lease cask and railcar

- TCRY facility capability, flexibility, access, and convenience
- $\quad \mathrm{S} \& \mathrm{~V}$ data collected for long distance traveled lack a controlled environment, which makes correlation to finite element modeling difficult.

- Data collection system chance for failure enroute

- Sources of S\&V forces occurring enroute not practically verifiable

- Limited rail travel not representative of routing for UNF shipment

- Not a modern rail cask

Cost

- Fabrication of basket and instrumentation lid

- Age and condition of NLIX railcar may require refurbishment of NLIX railcar or acquisition (lease) of alternative railcar and procurement of transport cradle for cask

S\&V = shock and vibration, SNL = Sandia National Laboratories, TCRY = Tri-City Railroad, $\mathrm{UNF}=$ used nuclear fuel 
Table ES-4. Summary of Option 4, Engineered Mass on a Railcar

Option 4 Highlights

- S\&V testing in a controlled environment with a engineered mass on a railcar at TCRY facility in Richland, Washington

- $\quad$ SNL and AREVA assemblies

- Flat deck railcar or depressed center railcar

- Potential for cross-county travel S\&V data collection with basket and surrogate assemblies

\begin{tabular}{|l|l|}
\hline \multicolumn{1}{|c|}{ Advantages } & \multicolumn{1}{c|}{ Disadvantages } \\
\hline Technical & Technical
\end{tabular}

- Flexibility in fabrication of mass to simulate size and weight of modern UNF transport casks

- Provides option to vary cask and test features in conducting rail test operations and collecting S\&V test data from surrogate components for comparison to results of computer-based simulations

- Provides ease of access to fuel assemblies for instrumentation

- Controlled test environment correlates to finite element modeling

- TCRY access to revenue track, if desired

- Cross-country trip representative of routing for UNF shipments

\section{Cost}

- Significantly reduced cost for simulated cask fabricated at TCRY, compared to cost to obtain use of a modern UNF rail cask transported to TCRY

- Optics of mass on a railcar (fabricated mass will not be a UNF transportation cask).

- Potential uncertainties due to concrete mass will be introduced by the simulation.

- $\quad \mathrm{S} \& V$ data collected for long distance traveled lacks a controlled environment which makes correlation to finite element modeling difficult.

- Data collection system chance for failure enroute

- Sources of S\&V forces occurring en route not practically verifiable

- Limited rail travel not representative of routing for UNF shipment

\section{Cost}

- Cost to design (including simulation analysis to verify that the surrogate mass characteristics are representative) and fabricate surrogate mass, surrogate basket, and cask cradle that model rail cask behavior

S\&V = shock and vibration, SNL = Sandia National Laboratories, TCRY = Tri-City Railroad, $\mathrm{UNF}=$ used nuclear fuel 


\section{CONTENTS}

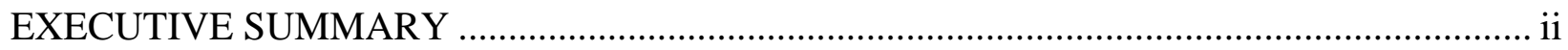

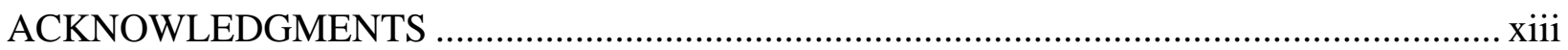

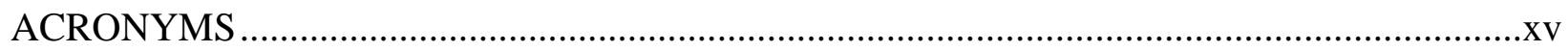

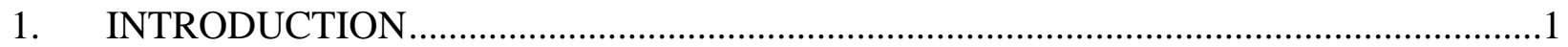

2. SHOCK AND VIBRATION TESTING OBJECTIVES ......................................................

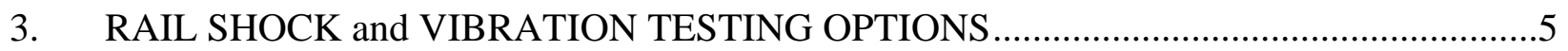

$3.1 \quad$ Rail S\&V Testing Option 1 ..................................................................................

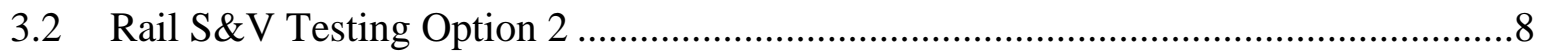

3.3 Rail Shock and Vibration Testing Option 3 .............................................................

3.4 Rail Shock and Vibration Testing Option 4 ……......................................................10

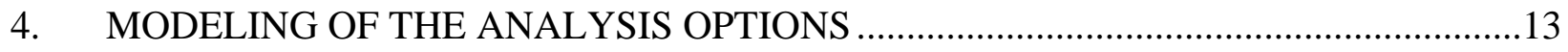

4.1 Two-Dimensional Railcar Modeling ......................................................................13

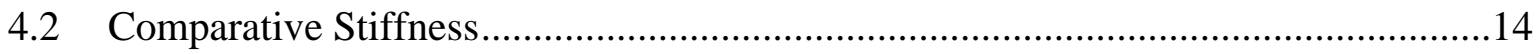

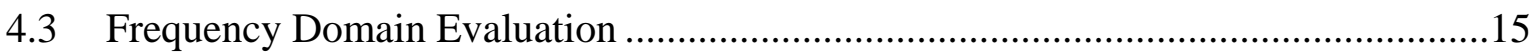

4.3.1 Modal Analysis ..........................................................................................15

4.3.2 Frequency Response Analysis .....................................................................16

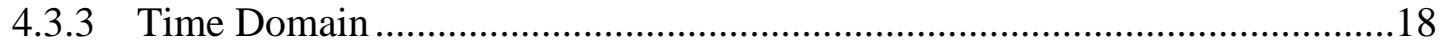

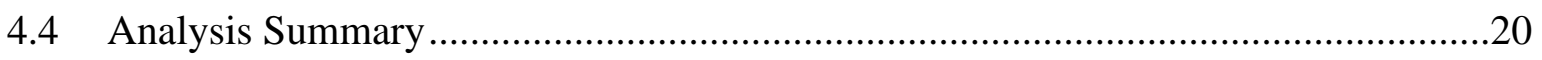

5. RAIL SHOCK AND VIBRATION ANALYSIS AND TESTING PROGRAM ….............23

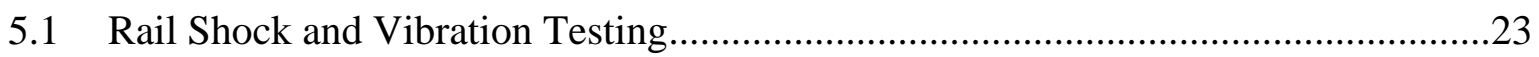

5.1.1 Railcar Options ..........................................................................................23

5.2 Approach for Creating Normal Rail Transportation Shock and Vibration

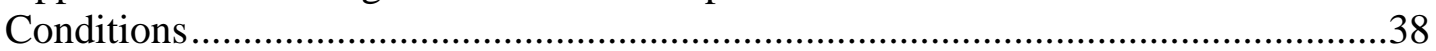

5.2.1 Potential Rail Test Environment Options ........................................................39

5.3 Approach for Computer Simulations and Analyses ..................................................43

5.3.1 Preliminary Modeling of Cask/Cradle.............................................................43

5.3.2 Pre-test Simulations for Stationary Tests ........................................................44

5.3.3 Post-Test Simulations ..............................................................................44

5.3.4 Shaker Test Modeling...................................................................................45

5.4 Test Instrumentation Approach and Methods.............................................................45

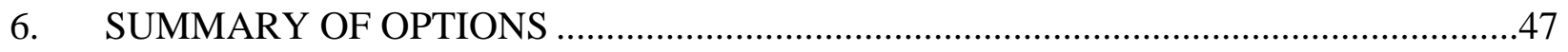

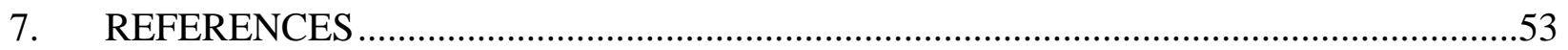




\section{FIGURES}

4-1. Two Dimensional Railcar System Dynamic Models. ..................................................... 13

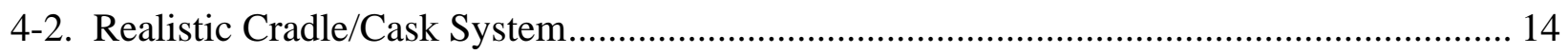

4-3. Equivalent Mass Concrete Block with Basket/Assembly Test Unit on Top...................... 14

4-4. Concrete Block with Mock Basket............................................................................. 15

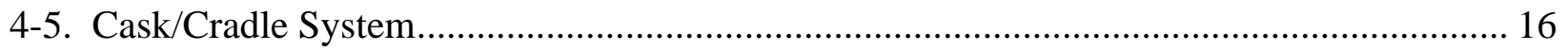

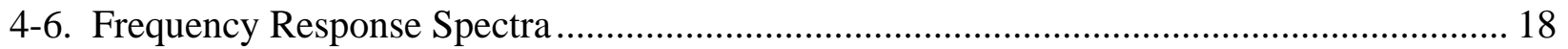

4-7. Detailed Cradle System Model with Detailed Fuel Assembly in One Fuel

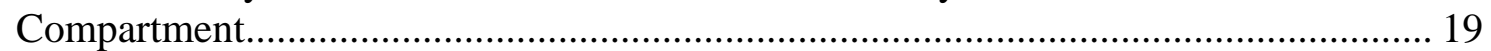

4-8. Concrete System Model with Detailed Fuel Assembly in Basket..................................... 19

4-9 - Nonlinear Analysis of Load Transference ................................................................. 20

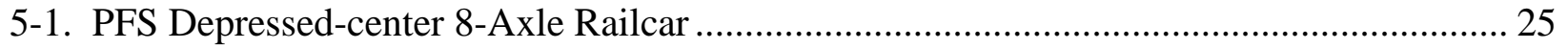

5-2. Dimensions and General Configuration of 8-Axle Depressed-center Railcar .................... 25

5-3. Dimensions and General Configuration of 8-Axle Flatcars ............................................ 26

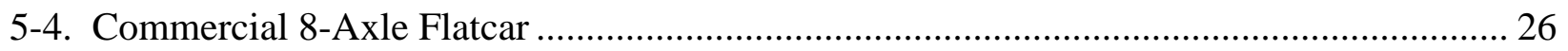

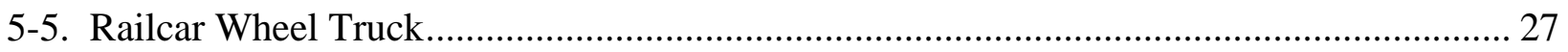

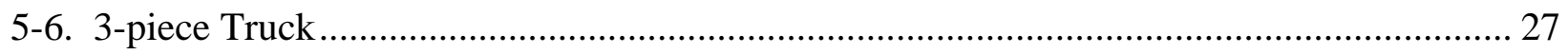

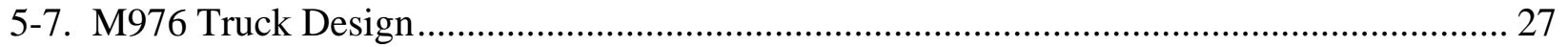

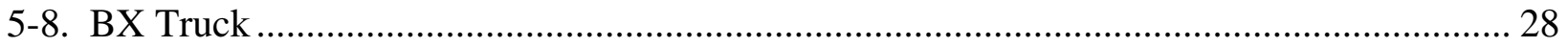

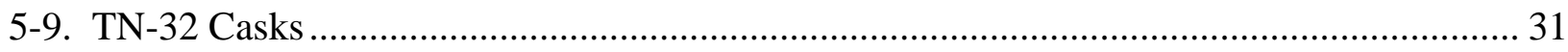

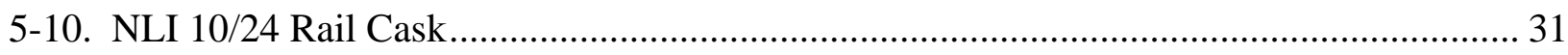

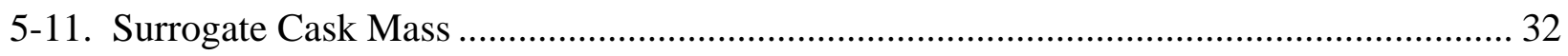

5-12. TMI Fuel Debris Shipping Cask on Transport Cradle on 8-Axle Railcar......................... 34

5-13. Artist's Illustration of Cask on Transport Cradle ............................................................ 34

5-14. Simple Beam Structure Transport Cradle................................................................... 35

5-15. Simple Support Structure for Large, Heavy Load .......................................................... 35

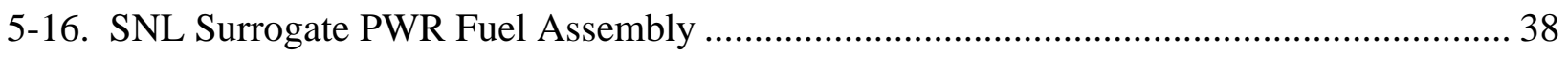

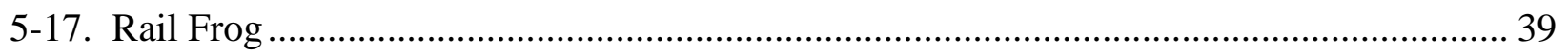

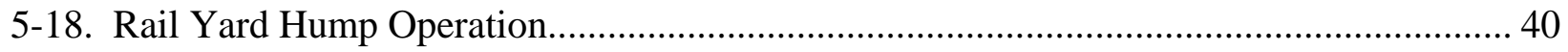

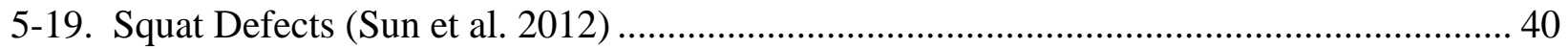

5-20. 40 mm Wheel Flats, Speed 70 km/h, and Axel Load 22 t (Iwnicki . 2006) ..................... 41

5-21. Corrugated Rail (Australian Rail Track Corporation, Ltd. 2006) .................................... 41 
5-22. Railcar Instability Because of Differences in Track Cant (Shust 1111) (with

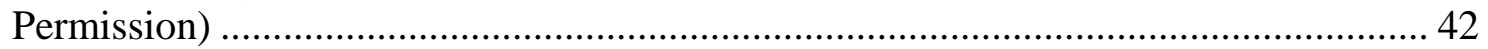

5-23. Hunting Oscillation (Iwnicki et al. 2006) (with permission).......................................... 42

\section{TABLES}

ES-1. Summary of Option 1, TN-32 (Tri-City Railroad) .................................................... iv

ES-2. Summary of Option 2, TN-32 (Dominion) …...........................................................

ES-3. Summary of Option 3, NLI 10/24 ............................................................................. vi

ES-4. Summary of Option 4, Engineered Mass on a Railcar................................................. vii

3-1. Summary of Rail Shock and Vibration Testing Options ................................................. 6

4-1. Modal Analysis of Concrete Block and Cask/Cradle Systems ....................................... 16

5-1. Railcar Options for Rail Shock and Vibration Test Program ........................................... 24

5-2. Shipping Cask Options for Rail Shock and Vibration Test Program ................................ 29

5-3. Transport Cradle Options for Rail Shock and Vibration Testing Program ........................ 33

5-4. Surrogate Fuel Assembly Options for Rail Shock and Vibration Testing Program............. 37

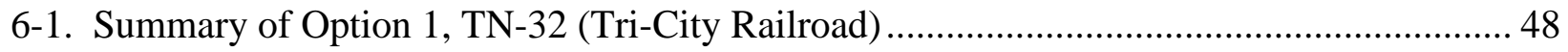

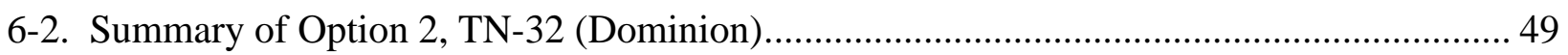

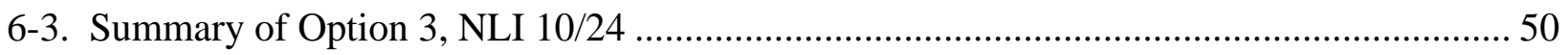

6-4. Summary of Option 4, Engineered Mass on a Railcar .................................................. 51 


\section{ACKNOWLEDGMENTS}

The authors, Steven B. Ross, Ralph E. Best, Nicholas A. Klymyshyn, Philip J. Jensen, and Steven J. Maheras all of Pacific Northwest National Laboratory (PNNL), would like to thank Harold Adkins (PNNL), Justin Coleman (Idaho National Laboratory) and Paul McConnell (Sandia National Laboratories) for their contributions to this report. The authors would like to thank Brian Koeppel (PNNL), for performing the technical peer review.

The authors would also like to thank Cornelia Brim, PNNL technical communications specialist, for editing assistance. 


\section{ACRONYMS}

$\begin{array}{ll}\text { AAR } & \text { Association of American Railroads } \\ \text { BWR } & \text { boiling water reactor } \\ \text { CG } & \text { center of gravity } \\ \text { DOE } & \text { U.S. Department of Energy } \\ \text { HBU fuel } & \text { high-burnup used nuclear fuel } \\ \text { NAC } & \text { Nuclear Assurance Corporation } \\ \text { NCS } & \text { normal conditions of storage } \\ \text { NCT } & \text { normal conditions of transportation } \\ \text { NRC } & \text { U.S. Nuclear Regulatory Commission } \\ \text { PNNL } & \text { Pacific Northwest National Laboratory } \\ \text { PWR } & \text { pressurized water reactor } \\ \text { S\&V } & \text { shock and vibration } \\ \text { SNL } & \text { Sandia National Laboratories } \\ \text { TRCY } & \text { Tri-City Railroad } \\ \text { TTCI } & \text { Transportation Technology Center, Inc. } \\ \text { UFDC } & \text { Used Fuel Disposition Campaign } \\ \text { UNF } & \text { used nuclear fuel }\end{array}$




\section{USED FUEL RAIL SHOCK AND VIBRATION TESTING OPTIONS ANALYSIS}

\section{INTRODUCTION}

The mission of the Used Fuel Disposition Campaign (UFDC) is in part to develop the technical bases needed to support extended storage of used nuclear fuel (UNF) and associated transportation. The objectives of the transportation activities are to address identified highpriority technical issues as well as to support the Nuclear Fuels Storage and Transportation Planning Project effort to remove UNF from shutdown nuclear power plant sites and to transport of the UNF to a consolidated storage site. This includes developing the technical basis for the transport of high-burnup used nuclear fuel (HBU fuel) and the transport of all used nuclear fuel after extended storage. This work will be closely integrated with the science and technology (S\&T) Experiments and S\&T Engineering Analysis Control Accounts in obtaining cladding material properties and cladding performance. It will also focus on field-testing to assess realistic loading on the fuel rods and assemblies during normal transport in order to obtain data needed to evaluate the integrity of fuel. This is a multi-year effort, investigating a range of issues pertaining to the development of the required data to establish the technical basis for transportation.

As discussed in a report on used fuel performance characterization (Adkins et. al, 2013a) under U.S. Nuclear Regulatory Commission (NRC) regulations, it is not sufficient for UNF to simply maintain its integrity during the storage period. It must maintain its integrity in such a way that it can withstand the physical forces of handling and transportation associated with restaging the fuel and moving it to a different location (such as an interim storage site, a geologic repository, or a treatment/recycling facility). Hence, understanding mechanical performance under cumulative loading stemming from normal conditions of storage (NCS), transfer (from storage container to transport container if needed), and normal conditions of transport (NCT) is necessary as it establishes part of the safety basis by maintaining the fuel confining boundary (geometry) and criticality safety, and is one of the critical components to the preservation of retrievability. Because of this, an important part of UFDC research and development is related to the mechanical loads on used nuclear fuel, cladding, and key structural components of the fuel assembly during NCT and NCS, and the response of the used fuel and assembly to those loads.

The purpose of this study is to identify and compare options for conducting tests that would simulate shock and vibration forces on used nuclear fuel assemblies that would occur under normal conditions of railroad transportation. To meet its research objectives, this report focuses on the possible rail transport shock and vibration testing options including potential casks, railcars, testing environment, and instrumentation considerations. It is planned that the used nuclear fuel transportation casks will be shipped to a potential interim storage site or repository using railcars that are manufactured and certified in accordance with Association of American Railroads (AAR) Standard S-2043, "Performance Specification for Trains Used To Carry HighLevel Radioactive Material” (AAR 2008), which the AAR issued for transporting used nuclear fuel. This standard includes special requirements for railcar coupling systems, brakes, nondestructive examination, and dynamic load tests. All S-2043 railcars are required to have 
safety performance monitoring systems that are active whenever the train is running. These requirements will be considered, as practicable, in the railcar selected for testing, as these requirements may impact shock and vibration performance. However, the structural design requirements for the AAR Standard S-2043 railcar for the spent fuel transportation trains are the same as those for regular depressed-center freight cars or flat deck cars.

Numerical modeling is a key companion to the proposed test series. Whatever test option is chosen will become the basis for modeling study. The physical response data collected through the test series will be used to validate the numerical model of the conveyance system. This step is required because conveyance systems are complex dynamic systems, and no single test of one particular system would be representative of all combinations of fuel/cask/conveyance designs. Fuel response results from the test series, such as strain measurements, need to be considered in the context of the conveyance system in which they were generated. Numerical modeling will characterize the system for the purpose of defining and documenting the test conditions. Once the system is characterized with a validated model, numerical analysis can extend beyond the limits of the test to investigate the most bounding response cases. A more forward-looking benefit is that the validated model methodology could be used to evaluate and certify new conveyance system designs.

Note that the focus of this report is to consider options for a physical test system. While modeling is an important feature of the test program, the supporting modeling program will not change significantly depending on the test option chosen. Section 4.0 provides an analysis of the testing options using a number of analytical approaches. A summary of the modeling that is expected to be performed in parallel to testing is presented in Section 5.2.

The follow on work in FY 2015 is to prepare a detailed test plan using the chosen testing option(s) as a basis. 


\section{SHOCK AND VIBRATION TESTING OBJECTIVES}

This section outlines a program of analyses, tests, and testing options that are designed to provide data and results that will establish the technical basis for predicting the effects of shock and vibration that occurs during normal rail transportation on the integrity of fuel rod cladding in high-burnup used nuclear fuel assemblies. Confidence that the integrity of fuel rod cladding will be maintained during normal transport is essential to ensure that the configuration of used nuclear fuel assemblies within a shipping cask, a safety related feature, will not change.

Cost and safety considerations preclude conducting in-the-field tests that could collect data on the effects of rail transportation shock and vibration on HBU fuel discharged from commercial nuclear power reactors. Consequently, a coordinated program is being designed that employs computer modeling and analysis and physical testing using surrogates for HBU fuel assemblies and rail transportation systems. The objectives of this program of analysis and testing are as follows:

1. Develop, demonstrate, and validate computer models that simulate responses of highburnup nuclear fuel rod structures within nuclear fuel assemblies contained in used fuel shipping casks and subjected to the shock and vibration that would be incident to normal rail transportation. These computer models will address the variability of cask, cradle, and rail car configurations.

2. Conduct a program of static and dynamic computer simulations, and on-the-rail operational tests that subjects surrogates for HBU fuel assemblies (fuel rod surrogates and fuel assembly structure surrogates) to shock and vibration conditions that simulate (or conservatively approximate) those for fuel assemblies contained in state-of-the-art shipping casks transported on AAR Standard S-2043 railcars in dedicated train service on U.S. railroad systems.

3. Collect surrogate fuel rod, surrogate fuel assembly, cask system (or surrogate), and railcar component strain and acceleration data that are sufficient to determine the strain and acceleration responses of the test components subjected to static tests, dynamic simulation tests, and on-the-rail operational tests that are designed to produce normal rail transportation shock and vibration forces,

4. Correlate results of computer model simulations to results obtained from the physical tests. Here the objective is to develop confidence that computer models used to simulate the performance of surrogate fuel assemblies will, with modifications to represent the properties of HBU fuel, provide valid results for the responses of HBU fuel to shock and vibration that will occur during normal rail transportation. 


\section{RAIL SHOCK AND VIBRATION TESTING OPTIONS}

This section discusses four primary options for conducting on-the-rail shock and vibration tests to determine the responses of UNF rods and cladding to the resulting forces of normal conditions of rail transportation. These options are listed in Table 3-1. Each of the four primary options has suboptions that integrate a collection of the components described in this report and that will require further decisions when a primary option is chosen. The advantages and disadvantages of these various options are discussed in detail in Section 5. Two of the primary options would use TN-32 casks, one would use the NLI 10/24 cask, and one would use a surrogate cask mass. All four of the integrated options would require use of computer simulations to determine locations for placement of instruments, and all would compare test results with results of computer simulations to help validate the computer models. Tri-City Railroad ${ }^{\mathrm{a}}$ (TCRY), a rail company located in Richland, Washington, has been identified to provide rail testing support including use of locomotives, use of local track for testing conditions, and other activities to support the Rail Shock and Vibration (S\&V) Test Program. However, other providers of rail testing support could be considered to support the objectives of this program. In addition, designs of a surrogate for a cask shipping cradle, a simulated cask mass, dummy fuel assemblies, and/or surrogate fuel basket structures that would be used in several of the test options would need to be based on simulation analyses. These simulations would determine the responses of real cask and fuel assembly components to $\mathrm{S} \& \mathrm{~V}$ forces and use the resulting information to guide the design of surrogates that respond similarly to the forces. Ultimately, one or more options will be chosen, and used along with the considerations presented in this report to develop a final rail shock and vibration test plan.

Common to all options are the surrogate fuel assemblies available for testing. These are the Sandia National Laboratories (SNL) assembly, AREVA assemblies, and un-instrumented fuel assembly surrogates. The structural characteristics of the SNL assembly are similar to and differ from those of high-burnup nuclear fuel. Similarities include the weight of the assembly, placement of flow control grids along the length of the assembly, guide tubes that connect the assembly's top and bottom end fittings, weight of fuel rods, fuel rods that have Zircaloy-4 cladding that surrounds simulated fuel, and simulated fuel that has approximately the same density as $\mathrm{UO}_{2}$ fuel pellets. Also, the SNL surrogate assembly has a $17 \mathrm{X} 17$ rod configuration, which is representative of state-of-the-art PWR fuel assemblies.

Differences include the fact that the fuel rod cladding is not irradiated in a reactor and as a consequence has not been subjected to neutron radiation work hardening, does not have precipitated zirconium hydride platelets dispersed in its structure, has not been thinned by surface oxidation, and has not been distorted by interactions with fuel pellets. Also, the surrogate fuel assembly's fuel rods do not have internal gas pressure. $\mathrm{UO}_{2}$ fuel pellets are simulated with an elemental lead rod that is undivided over its full length. In addition, to make it possible to insert the lead rod into the cladding, it was necessary for the diameter of this rod to be slightly less than the inside diameter of the cladding.

\footnotetext{
${ }^{\mathrm{a}}$ http://www.tcry.com/
} 
AREVA may also provide a surrogate PWR fuel assembly or assemblies that will also be instrumented for the rail shock and vibration test program. It is likely the surrogate fuel assemblies provided by AREVA will represent state-of-the-art 17X17 design configurations used in the North Anna nuclear power reactors. As part of the overall program, AREVA has proposed to use its Lynchburg, Virginia Research Facility shaker-table to conduct shock and vibration tests on fuel assemblies it would instrument and place into instrumented sections of a TN-32 cask's basket. These tests would be coordinated with the rail operational tests to be conducted at TCRY in Richland, Washington. The shaker-table tests would also use shock and vibration power spectral density function inputs that would be developed in computer simulations performed at PNNL.

One of the benefits of instrumenting both the SNL and AREVA assemblies includes the different assembly design and the presence of pellets in the AREVA assemblies where the SNL assembly contains a solid lead rope. This will allow understand of any difference because of pellet-pellet interactions.

Table 3-1. Summary of Rail Shock and Vibration Testing Options

\begin{tabular}{cll}
\hline Option & Description & Proposed Location \\
\hline 1 & $\begin{array}{c}\text { TN-32 Cask Testing in transit and } \\
\text { at TCRY facility }\end{array}$ & AREVA Lynchburg, Virginia Facilities \\
& Shaker table testing at AREVA & TCRY Facilities - Richland, Washington \\
& facilities & $\begin{array}{l}\text { Also potential to test while being transported from } \\
\text { AREVA facilities to Richland, Washington }\end{array}$ \\
2 & TN-32 Cask Testing in transit & $\begin{array}{l}\text { While in transit from the PCC Facility in York, } \\
\text { Pennsylvania to CHT in North Carolina }\end{array}$ \\
3 & NLI 10/24 Cask Testing & TCRY Facilities - Richland, Washington \\
4 & Mass on a railcar testing & TCRY Facilities - Richland, Washington \\
\hline
\end{tabular}

CHT = Columbiana High Tech, TCRY = Tri-City Railroad, PCC= Precision Components Corporation

\subsection{Rail S\&V Testing Option 1}

This option for conducting the rail S\&V tests would use a TN-32 cask provided by AREVA that is a "sister" cask to the one to be used in the DOE/Industry Used Nuclear Fuel Dry Storage Demonstration Project. For this option, it is assumed that AREVA would provide the cask with its internal basket structure, a test-head that provides pass-through access to the cask's interior for instrumentation leads, a transport cradle, and a railcar. Strain gauges and accelerometers would be installed on the cask, shipping cradle, and cask basket at locations determined collaboratively by AREVA and the Rail S\&V Test Program. The Rail S\&V Test Program team would also collaborate with AREVA to select the depressed-center railcar or a flatcar and associated wheel trucks that would be used. In selecting the railcar, the Program would use information available from the AAR and Transportation Technology Center, Inc. (TTCI), to identify a selection of modern freight railcars whose design meets requirements that approach those specified in AAR Standard S-2043. This testing option could include shaker table testing at 
AREVA facilities prior to shipment to TCRY and testing by an SNL/Pacific Northwest National Laboratory (PNNL) team. In addition, for this option, the TN-32 cask could be instrumented for the trip to the TCRY facilities in Richland, Washington. The extent of that data collection, including location of instruments, will need to be developed as part of the detailed test plan if this option is chosen.

There are three options for surrogate fuel assemblies that would be loaded into the cask's basket (sometimes referred to as mock or simulated fuel assemblies, and hereafter referred to as surrogate). These are:

1. For the first fuel assembly option, 32 surrogate pressurized water reactor (PWR) fuel assemblies would be provided by AREVA with instrumentation installed on a selected number of these assemblies. The surrogate assemblies could be installed in the cask by AREVA before it is shipped to the TCRY facility in Richland, Washington, or they could be installed at the TCRY facilities during preparations for the rail S\&V tests. AREVA and the Rail S\&V Test Program would collaborate to determine the types and placement of instruments on selected surrogate fuel assemblies and the placement of these assemblies in the cask's basket. AREVA proposes to record responses of the instrumented cask and surrogate fuel assemblies to in-transit shock and vibration forces if the surrogate assemblies are in the cask when it is shipped by rail from its current location in Pennsylvania to the TCRY site. This option would include the expense of fabricating a significant number of surrogate PWR fuel assemblies.

2. For the second fuel assembly option, three types of surrogate fuel assemblies would be placed into the cask's basket at the TCRY facilities in Richland, Washington:

a. the surrogate 17X17 PWR fuel assembly that has instrumentation installed and was used in the shaker-table and truck tests conducted by SNL in FY 2013 and FY 2014.

b. an instrumented surrogate PWR fuel assembly that would be provided by AREVA. AREVA and the Rail S\&V Test Program would collaborate to determine the types and placement of instruments on the surrogate fuel assembly.

c. Thirty un-instrumented dummy masses that weigh the same as fuel assemblies and impart reaction forces on the cask basket that would be similar to forces from actual fuel assemblies. The Rail S\&V Test Program team would design the dummy masses.

3. For the third fuel assembly option, two types of mock fuel assemblies would be placed into the cask's basket at TCRY:

a. the surrogate 17X17 PWR fuel assembly that has instrumentation installed and was used in the shaker-table and truck tests conducted by SNL in FY 2013 and FY 2014.

b. Thirty-one surrogate PWR fuel assemblies that would be provided by AREVA, one of which would be instrumented. AREVA and the Rail S\&V Test Program would collaborate to determine the types and placement of instruments on the surrogate fuel assembly. 


\subsection{Rail S\&V Testing Option 2}

This option for conducting the rail shock and vibration tests would use the AREVA TN-32 cask that will be loaded with high-burnup nuclear fuel for the U.S. Department of Energy (DOE)/Industry Used Nuclear Fuel Dry Storage Demonstration Project. The dry storage demonstration project will be conducted at Dominion Power Corporation's North Anna nuclear power plant site. However, before it is used in the dry storage project to store used nuclear fuel, the TN-32 cask will be transported from its present location in York, Pennsylvania (Precision Components Corporation Facility) to a Greensboro, North Carolina facility (Columbiana High Tech) where it will be returned to as-new condition. Before this shipment occurs AREVA would install a test-head that provides pass-through access to the cask's interior for S\&V instrumentation leads and a transport cradle.

The Rail S\&V Testing Program team would also collaborate with AREVA to select the depressed-center railcar or a flatcar and associated wheel trucks that would be used. In selecting the railcar, the Rail S\&V Program would use information available from the AAR and TTCI to identify a selection of modern freight railcars whose design meets requirements that approach those specified in AAR Standard S-2043.

Strain gauges and accelerometers would be installed on the fuel rods and on the cask, shipping cradle, and cask basket at locations determined collaboratively by AREVA and the Rail S\&V Test Program. The Rail S\&V Test Program would also collaborate with AREVA to select and install instrumentation on the depressed-center railcar or a flatcar and associated wheel trucks that would be used. AREVA proposes to record the responses of the instrumented cask and surrogate fuel assemblies to shock and vibration forces when it is shipped to the North Carolina facility. Time and budget permitting, more extensive movement over a wide range of rail routes could occur. Expanding from a single route to multiple cross-country routes to collect S\&V data would help ensure that the range of shock and vibration forces and cask and fuel assembly responses that are recorded would encompass those that will be experienced when moving UNF from nuclear power plant sites in 34 states.

There are two options for surrogate fuel assemblies that would be loaded into the cask's basket:

1. Thirty-two surrogate PWR fuel assemblies would be provided by AREVA with instrumentation installed on a selected number of these assemblies. The surrogate assemblies could be installed in the cask by AREVA before it is shipped to the North Carolina facility. AREVA and the Rail S\&V Test Program would collaborate to determine the types and placement of instruments on selected surrogate fuel assemblies and the placement of these assemblies in the cask's basket. AREVA proposes to record responses of the instrumented cask and surrogate fuel assemblies to shock and vibration forces during the rail transport of the cask from its current location in Pennsylvania to the North Carolina facility.

2. Three types of surrogate fuel assemblies would be placed into the cask's basket before it was shipped from the current location in Pennsylvania:

a. one or more instrumented surrogate PWR fuel assemblies would be provided by AREVA. AREVA and the Rail S\&V Test Program would collaborate to determine the 
types and placement of instruments on selected surrogate fuel assemblies and the placement of these assemblies in the cask's basket.

b. the surrogate 17X17 PWR fuel assembly that has instrumentation installed and was used in the shaker-table and truck tests conducted by SNL in FY 2013 and FY 2014.

c. up to 30 un-instrumented dummy masses that weigh the same as fuel assemblies and impart reaction forces on the cask basket that would be similar to forces from actual fuel assemblies. AREVA and the Rail S\&V Project would collaborate to design the dummy masses.

\subsection{Rail Shock and Vibration Testing Option 3}

This option for conducting the rail shock and vibration tests would use an NAC-NLI 10/24 used nuclear fuel shipping cask and NLIX (or alternate) railcar. TCRY would provide the cask and railcar. The Rail S\&V Testing Program team and TCRY would collaborate to select the railcar that would be used in the tests. PNNL would design and acquire a simulated internal basket structure and a test-head that would provide pass-through access to the cask's interior for instrumentation leads. PNNL would also design and acquire a simulated transport cradle for the NLI 10/24 cask if the NLIX railcar, because of its condition, is not used in the tests. Strain gauges and accelerometers would be installed on the cask, its shipping cradle, and the simulated cask basket at locations determined by the Rail S\&V Test Program team. The Rail S\&V Test Program would also select and install instrumentation on the railcar and associated wheel trucks that would be used.

There are four options for surrogate fuel assemblies that would be loaded into the cask's basket:

1. For the first fuel assembly option, one or more surrogate PWR fuel assemblies would be provided by AREVA with instrumentation installed on a selected number of these assemblies. The surrogate assemblies would be installed at the TCRY facilities in Richland, Washington, during preparations for the rail S\&V tests. AREVA and the Rail S\&V Test Program would collaborate to determine the types and placement of instruments on selected surrogate fuel assemblies.

2. For the second fuel assembly option, three types of surrogate fuel assemblies would be placed into the cask's basket at the TCRY facilities in Richland, Washington:

a. the surrogate 17X17 PWR fuel assembly that has instrumentation installed and was used in the shaker-table and truck tests conducted by SNL in FY 2013 and FY 2014

b. an instrumented surrogate PWR fuel assembly that would be provided by AREVA. AREVA and the Rail S\&V Test Project would collaborate to determine the types and placement of instruments on the surrogate fuel assembly

c. The remaining positions filled with un-instrumented dummy masses that weigh the same as fuel assemblies and impart reaction forces on the cask basket that would be similar to forces from actual fuel assemblies. The Rail S\&V Program would design the dummy masses.

3. For the third fuel assembly option, two types of surrogate fuel assemblies would be placed into the cask's basket at the TCRY facilities in Richland, Washington: 
a. the surrogate 17X17 PWR fuel assembly that has instrumentation installed and was used in the shaker-table and truck tests conducted by SNL in FY 2013 and FY 2014

b. The remaining positions filled with surrogate PWR fuel assemblies that would be provided by AREVA, one of which would be instrumented. AREVA and the Rail S\&V Test Project would collaborate to determine the types and placement of instruments on the surrogate fuel assembly.

4. For the fourth fuel assembly option, two types of surrogate fuel assemblies would be placed into the cask's basket at the TCRY facilities in Richland, Washington:

a. the surrogate 17X17 PWR fuel assembly that has instrumentation installed and was used in the shaker-table and truck tests conducted by SNL in FY 2013 and FY 2014.

b. The remaining positions filled with un-instrumented dummy masses that weigh the same as fuel assemblies and impart reaction forces on the cask basket that would be similar to forces from actual fuel assemblies. PNNL would design the dummy masses.

\subsection{Rail Shock and Vibration Testing Option 4}

This option for conducting the rail shock and vibration tests would use an engineered (or surrogate cask) mass designed by the Rail S\&V Testing Program team that would simulate the size, weight, and structural stiffness of a modern, large rail transportation cask. The simulated cask mass would also include an internal basket structure designed to simulate the response of the fuel-assembly basket in a modern rail transportation cask to the forces resulting from shock and vibration during normal rail transportation. In addition, a cradle will be fabricated that would duplicate the expected response of an actual cradle. The desired outcome is a fabricated system that responds to shock and vibration forces similar to the responses of an actual rail cask system.

The Rail S\&V Test Program would select a modern depressed-center freight railcar or flatcar and the associated wheel trucks that would be used to carry the engineered cask mass and cradle. In selecting the railcar, the program would use information available from the AAR and TTCI to identify a selection of modern freight railcars whose design meets requirements that approach those specified in AAR Standard S-2043. TCRY would provide the railcar. PNNL would also design a simulated cradle to support the engineered cask mass on the railcar. The simulated cradle would be designed to transmit forces between the cask mass and the railcar in the same manner as does the cradle used when transporting a large rail cask on a railcar. Here, the design and construction of a simulated transport cradle would be integrated with the design of the engineered cask mass. Emphasis would be placed on simplicity and simulation of the transfer of $\mathrm{S} \& \mathrm{~V}$ forces from the railcar to the cask mass. In addition, features could be included that would change the interaction of the railcar and the cradle and cask to simulate differences in shipping cradles designed to transport commercial rail casks. Strain gauges and accelerometers would be installed on the simulated cask, the shipping cradle, and the simulated cask basket. The Rail S\&V Test Program would also select and install instrumentation on the railcar and the associated wheel trucks that would be used.

The following are two options for surrogate fuel assemblies that would be loaded into the cask's basket: 
1. For the first fuel assembly option, one to four surrogate PWR fuel assemblies would be provided by AREVA with instrumentation installed on a selected number of these assemblies. The surrogate assemblies would be installed at TCRY facilities in Richland, Washington during preparations for the rail S\&V tests. AREVA and the Rail S\&V Test Program would collaborate to determine the types and placement of instruments on selected surrogate fuel assemblies.

2. For the second fuel assembly option, two types of surrogate fuel assemblies would be placed into the surrogate cask's basket at the TCRY facilities in Richland, Washington:

a. the surrogate 17X17 PWR fuel assembly that has instrumentation installed and was used in the shaker-table and truck tests conducted by SNL in FY 2013 and FY 2014

b. one or two instrumented surrogate PWR fuel assemblies that would be provided by AREVA. AREVA and the Rail S\&V Test Program would collaborate to determine the types and placement of instruments on the surrogate fuel assembly. 


\section{MODELING OF THE ANALYSIS OPTIONS}

The different test options considered in this report each have a different structural configuration, and this raises the question of how much the composition affects the loading transmitted to the fuel. At one extreme, the cask or representative mass configurations are sufficiently rigid that the only components to affect the dynamic response of the system are the railcar truck configuration, which can be easily modified for test purposes by swapping in different spring/damping packages. Another possibility is that the cask or representative mass configuration has a strong influence on the loads transmitted from the track to the fuel, such that any test configuration needs to be carefully constructed or vetted to match existing or expected railcar behavior. A limited modeling campaign was conducted to determine whether or not the structural configuration of the test system was important, or if it was only necessary to capture the correct mass on the railcar. The results of this modeling campaign suggest that the test system configuration is vitally important to ensuring representative loading on the fuel.

\subsection{Two-Dimensional Railcar Modeling}

The initial modeling effort was performed using simplified representations of the railcar system to model two-dimensional (2D) motion. Two different cask surrogates were modeled on identical flatbed railcars: 1) an approximate TN-68 cask system and 2) a concrete block monolith of equivalent mass (Figure 4-1). Each model contained a point mass on a spring and damper to approximate an individual fuel assembly. When the models were subjected to the same dynamic disturbance at the trucks, the approximate TN-68 fuel assembly responded more strongly than the fuel assembly attached to the concrete mass by about 30 percent. These relatively simple models suggested the structural configuration of the test system could be important. Further modeling compared a more realistic cradle system to the concrete block of equivalent mass.
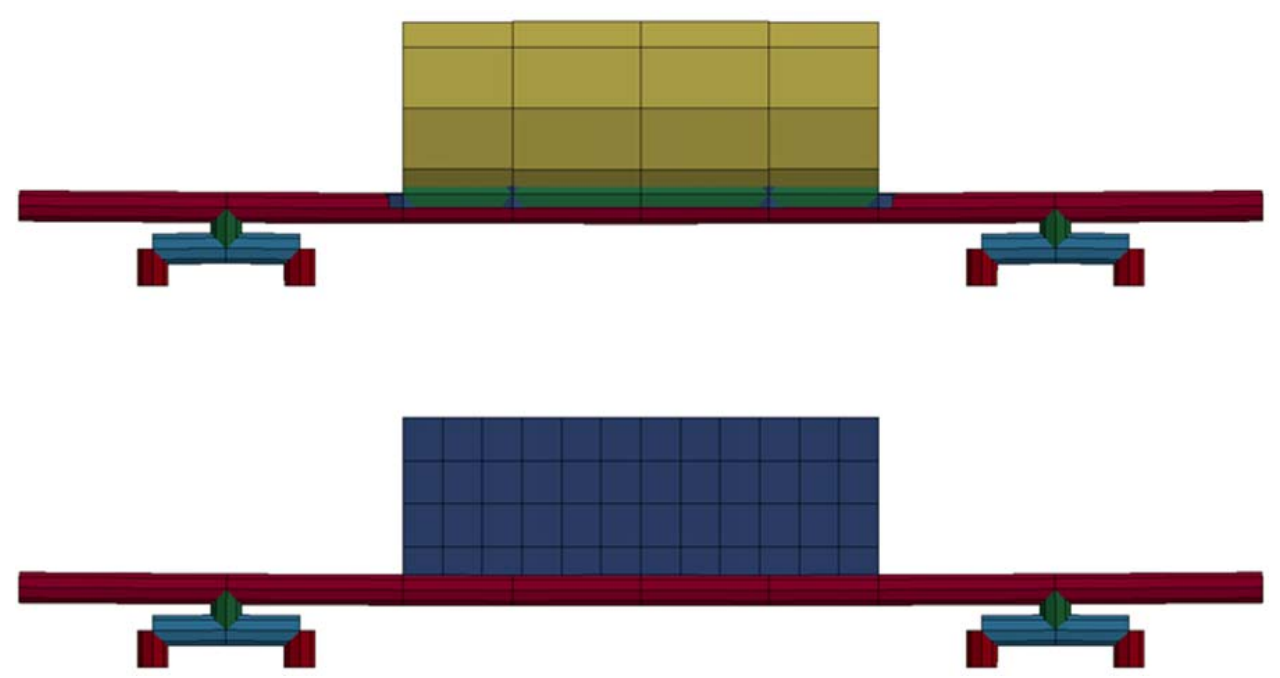

Figure 4-1. Two Dimensional Railcar System Dynamic Models. An approximate TN-68 cask system is in the top image, and a concrete block monolith of equivalent mass is in the bottom image. 


\subsection{Comparative Stiffness}

Detailed three-dimensional (3D) structural models were created to evaluate the stiffness of a realistic cradle supporting a TN-32 cask (Figure 4-2) and a concrete block of equivalent mass and footprint (Figure 4-3). The design of the cradle was inspired by photographs of actual cradles, but does not correspond to a known design. The stresses caused by the weight of a fully loaded cask were determined to be well within the yield strength of structural steel, so the simulated cradle design appears to be viable and a reasonable approximation of a realistic system.

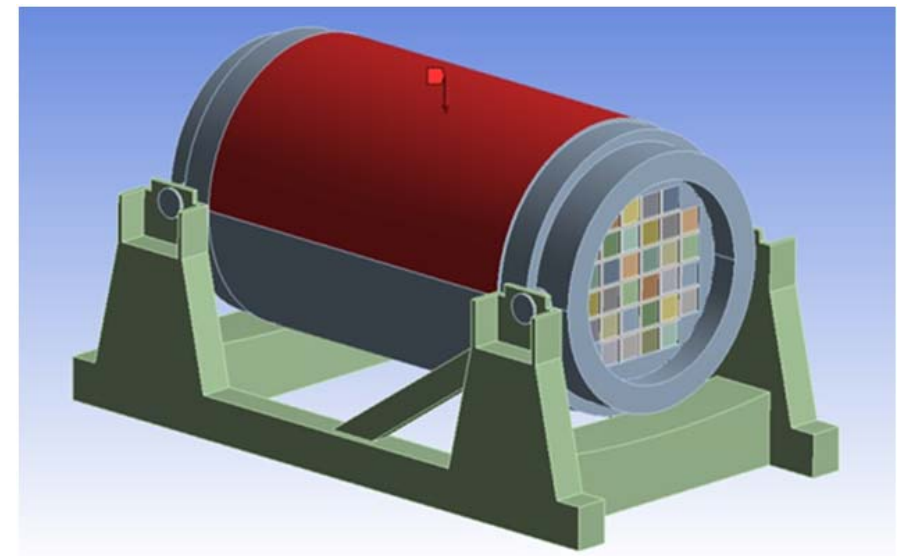

Figure 4-2. Realistic Cradle/Cask System

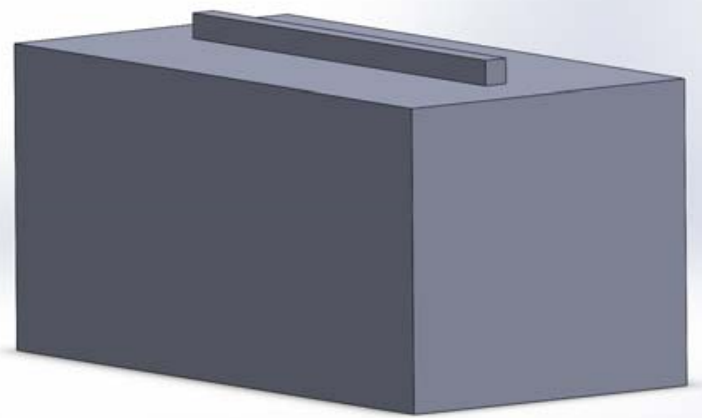

Figure 4-3. Equivalent Mass Concrete Block with Basket/Assembly Test Unit on Top

The effective vertical stiffness of the two structures was calculated by applying a vertical downward load to the top of the cask and topmost surface of the concrete block and dividing by the resulting displacement. The cask system was determined to have a representative stiffness of $1 \mathrm{E} 8 \mathrm{lb} / \mathrm{in}$. The concrete block was found to have a stiffness of $1 \mathrm{E} 9 \mathrm{lb} / \mathrm{in}$. when the load was distributed across the top face of the concrete (without the representative fuel basket block) and 3E8 lb/in. when the load was localized on the fuel basket block visible in Figure 4-3. Lower effective stiffness for the cask would tend toward a lower resonant frequency which is more susceptible to amplification for the low-frequency excitations expected under rail transportation. 
The dynamic difference is further evaluated using a frequency response analysis and a time history comparison for a shock pulse.

\subsection{Frequency Domain Evaluation}

Dynamic systems are often evaluated in the frequency domain because the dynamic response of structures depends on the frequency characteristics of the load. When a structure is loaded with a cyclical excitation that has a frequency near its natural frequency, a small magnitude load can be amplified to a large magnitude response to the extent that the structure may be damaged. Modal analysis is used to determine the natural frequencies of vibration of a structure, and frequency response analysis is used to determine the amount of response amplification over a range of frequencies.

\subsubsection{Modal Analysis}

A modal analysis for the concrete block and cask/cradle systems was performed in ANSYS R15.0. The concrete block and mock basket system that was input into ANSYS is shown in Figure 4-4, and the cask/cradle system is shown in Figure 4-5. The total weight for both systems is approximately 255,000 lb, the length for both systems is approximately $228 \mathrm{in}$, and the width for both systems is approximately 122 in. The modal analysis for each system was performed with the displacements of each base fixed.

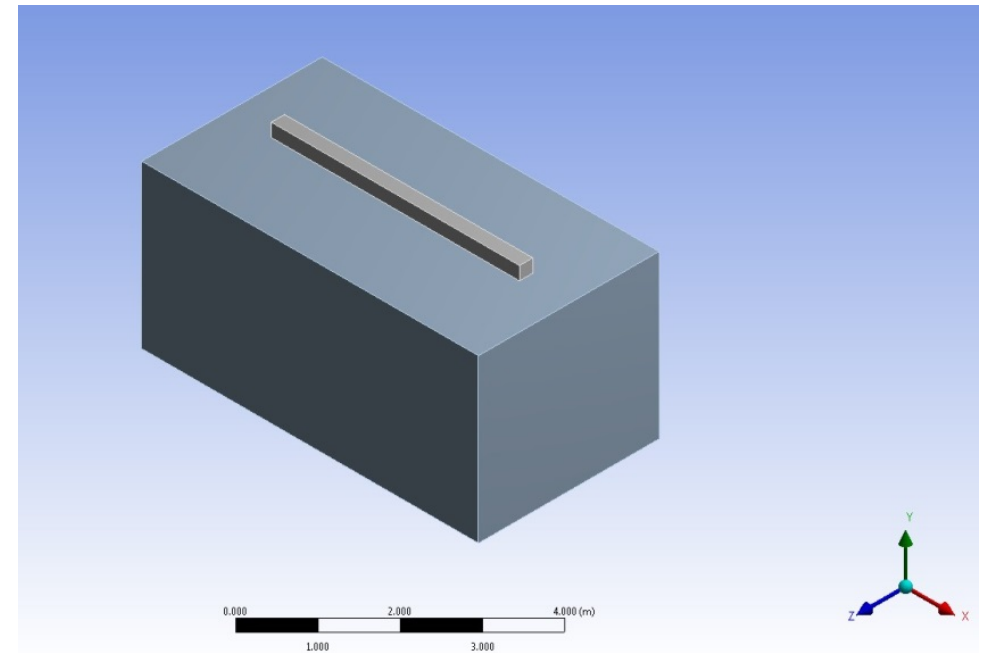

Figure 4-4. Concrete Block with Mock Basket

The results of the modal analysis for the concrete block system and the cask/cradle system are shown in Table 4-1. The natural frequencies of vibration of the structure and the corresponding deformation shapes associated with the first eight vibration modes were calculated. The relative strength of the modes is ranked by the amount of mass that participates in the deformation mode shape. The ratio value reported in Table 4-1 is a normalized mass participation value, with the strongest listed mode frequencies assigned a value of 1.0, with the other values normalized to that value. In the case of the concrete block, the strongest mode is $318.1 \mathrm{~Hz}$, with another relatively strong vibration mode at $338.2 \mathrm{~Hz}$. The cask/cradle system identifies vibration 
frequencies far below the concrete block, with the strongest frequency at $52.4 \mathrm{~Hz}$ and other relatively low strength vibration modes between 10.5 and $154.2 \mathrm{~Hz}$. Based on previous analytical work, the range of interest for a fuel assembly is below $100 \mathrm{~Hz}$ (Klymyshyn et al. 2013, and Adkins 2013b). This analysis shows that the concrete block system does not have any normal vibration modes below $144.3 \mathrm{~Hz}$, while the cask/cradle system's fundamental mode is within the range of interest at $52.4 \mathrm{~Hz}$. From modal analysis, we expect a cask/cradle system to behave in a significantly different manner to a concrete block system.

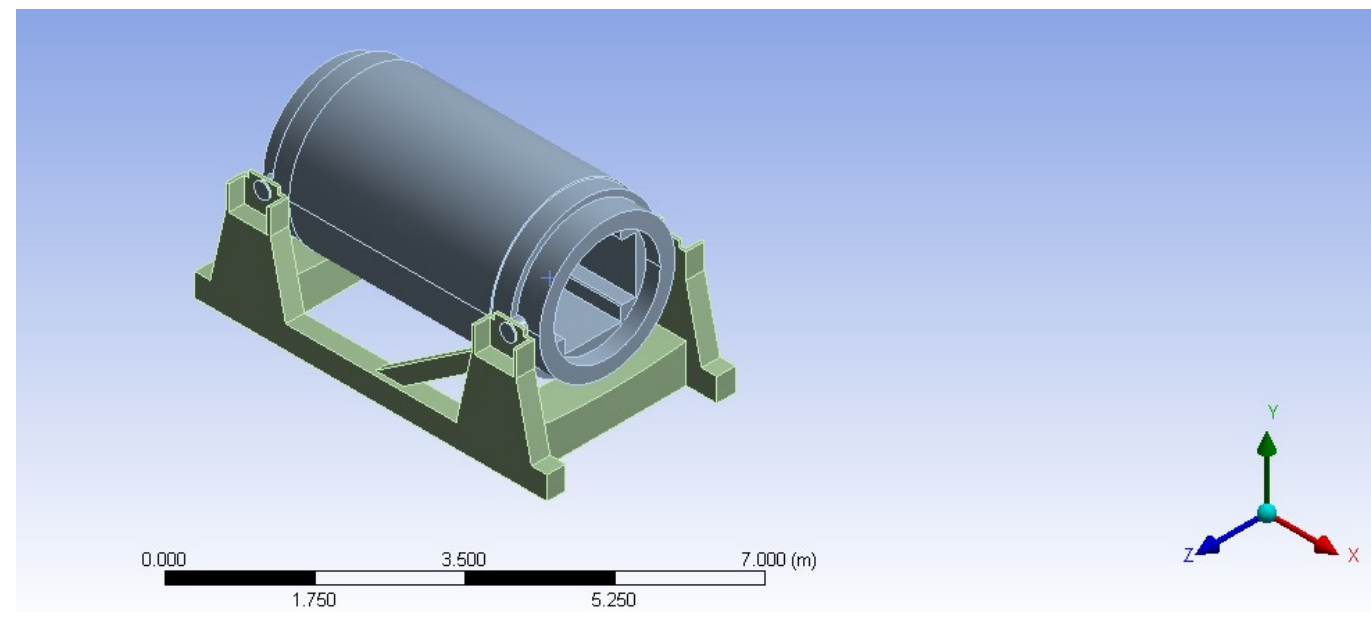

Figure 4-5. Cask/Cradle System

Table 4-1. Modal Analysis of Concrete Block and Cask/Cradle Systems

\begin{tabular}{|c|c|c|c|c|c|}
\hline \multicolumn{6}{|c|}{ Modal Analysis Vertical Direction } \\
\hline \multicolumn{3}{|c|}{ Concrete Block System } & \multicolumn{3}{|c|}{ Cask/Cradle System } \\
\hline Mode & Frequency & Ratio & Mode & Frequency & Ratio \\
\hline 1 & 144.3 & 0.0002 & 1 & 10.52 & 0.0004 \\
\hline 2 & 174.3 & 0.0000 & 2 & 27.72 & 0.0269 \\
\hline 3 & 179.0 & 0.0000 & 3 & 28.75 & 0.0012 \\
\hline 4 & 285.9 & 0.0004 & 4 & 52.40 & 1.0000 \\
\hline 5 & 318.1 & 1.0000 & 5 & 66.76 & 0.0033 \\
\hline 6 & 338.2 & 0.6429 & 6 & 73.06 & 0.0419 \\
\hline 7 & 347.9 & 0.0000 & 7 & 153.5 & 0.0503 \\
\hline 8 & 354.1 & 0.0000 & 8 & 154.2 & 0.0245 \\
\hline
\end{tabular}

\subsubsection{Frequency Response Analysis}

The modal analysis identifies the normal vibration frequencies of a structural system. Frequency response analysis calculates the response of the system when subjected to cyclical loads over a range of frequencies. In this case, the response spectra were calculated assuming a vertical acceleration load applied to the base of both systems with an amplitude of $1 \mathrm{~m} / \mathrm{s}^{2}$ and a frequency range of 1 to $100 \mathrm{~Hz}$. The response of the concrete system was measured at the basket, 
while the response of the cask and cradle system was measured at the top of the cask. It is assumed that the two locations are representative of the acceleration response of the fuel carried by each system. The modal analysis model of the cask and cradle case did not include an internal basket structure, so a point on the outside surface of the relatively rigid steel cask was chosen for comparison. The same models used for modal analysis were used in the frequency response analysis (the modal results are used in the frequency response calculation).

Figure 4-6 shows the frequency response spectra for both cases. A response value of 1.0 indicates that the peak acceleration response equals the input amplitude. A response value less than 1.0 indicates that the response is relatively lower than the input, and a response value greater than 1.0 indicates a relative amplification of the input. At about $35 \mathrm{~Hz}$ and higher the cask/cradle system exhibits amplification, with a maximum amplification of 10 times near 50 Hz. The modal analysis predicts a natural vibration frequency at $52.4 \mathrm{~Hz}$, so the frequency response analysis is appropriately showing resonance around that frequency. Conversely, the concrete block shows a low transmissibility through the entire frequency range of interest. Comparing the two curves, the cask/cradle response is more than an order of magnitude higher than the concrete block response. This indicates that the loads transmitted to the fuel assembly are potentially much greater in the cask/cradle case than the concrete case. To the point of this options analysis, if a concrete monolithic mass system is used as the test platform, it can potentially underrepresent the load on the fuel assembly and not be conservative. To get the desired response from the shock and vibration testing, the surrogate mass will need to be engineered to best represent the expected response from an actual rail cask. 


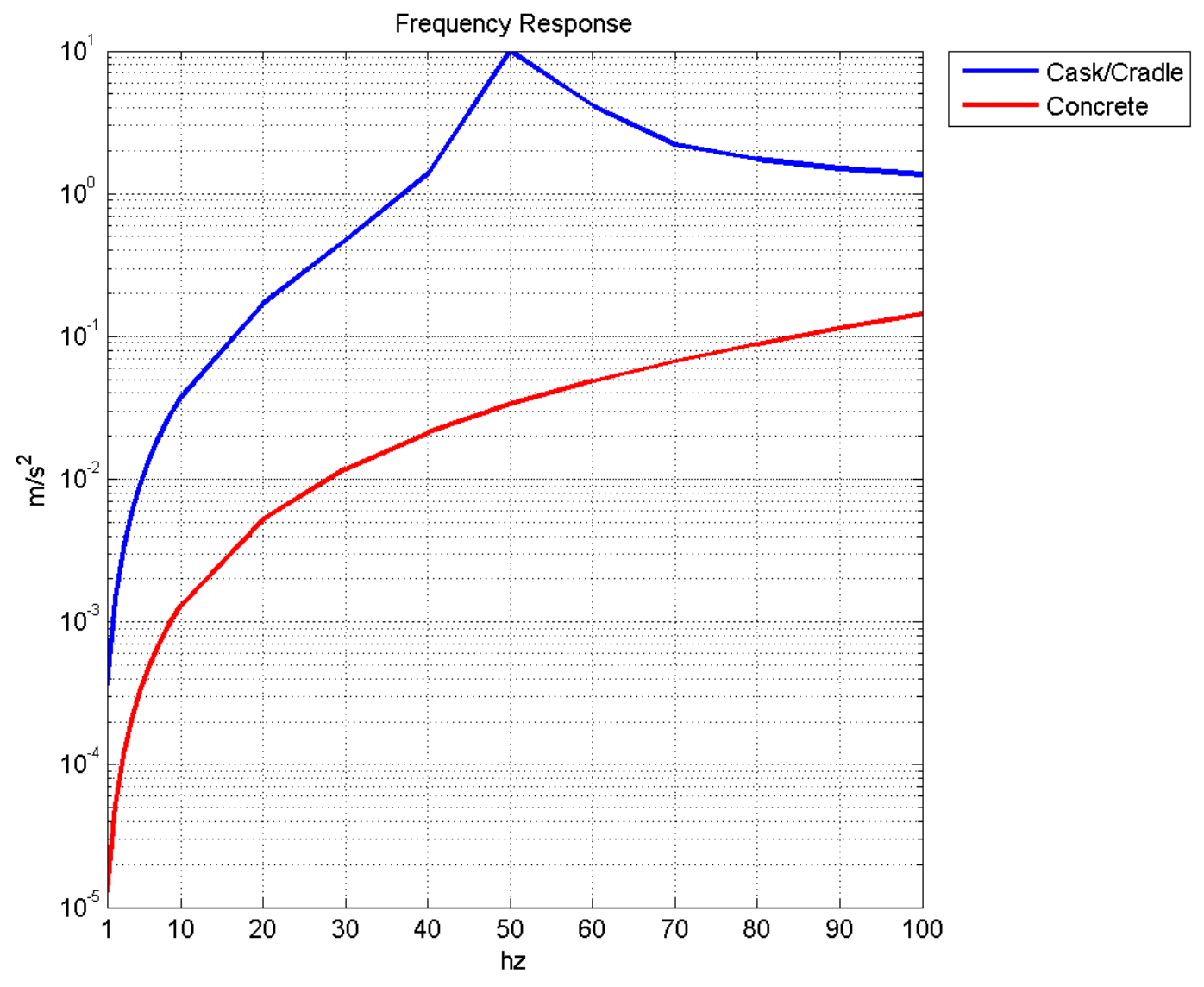

Figure 4-6. Frequency Response Spectra

\subsubsection{Time Domain}

The frequency domain evaluations used linear methods, but the fuel represents a nonlinear system because it has the freedom to move independently in the basket subject to friction and contact forces. One way to evaluate the nonlinear transmission of loads is through a time-domain model. For the two configurations of interest—cradle/cask and concrete block—a detailed fuel assembly model is added to the basket, and an identical shock acceleration load is applied to the base. A direct comparison can made between the responses of the fuel assembly in both configurations.

The two nonlinear time-domain models were evaluated using the LS-DYNA code, which is a commercially available general-purpose explicit finite element code. Figure 4-7 shows a cutaway view of the cask and cradle system, which roughly approximates the TN-32 cask. Figure 4-8 shows a cutaway view of the concrete system, which has an aluminum channel used as a basket surrogate. 


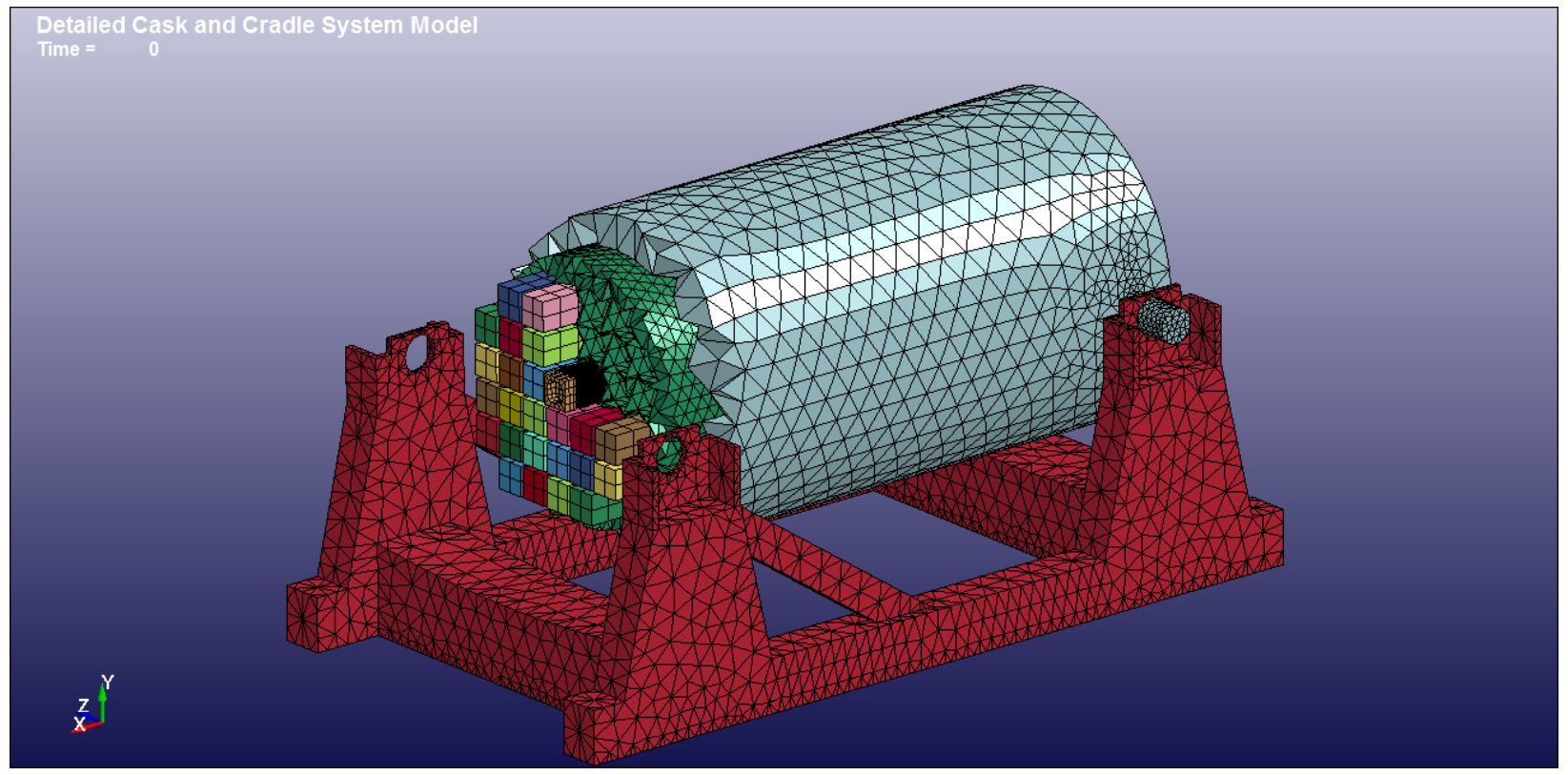

Figure 4-7. Detailed Cradle System Model with Detailed Fuel Assembly in One Fuel Compartment

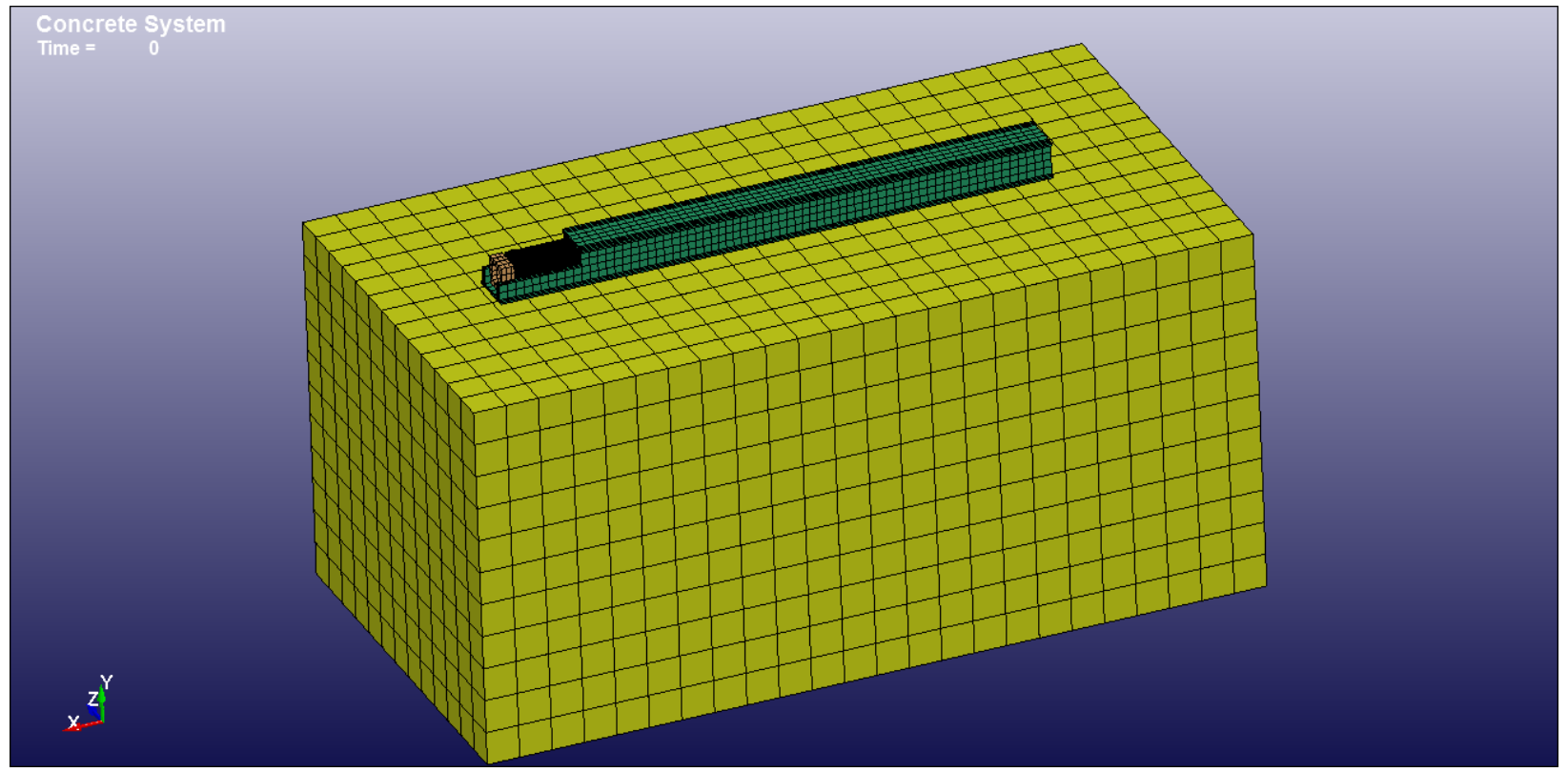

Figure 4-8. Concrete System Model with Detailed Fuel Assembly in Basket

Figure 4-9 summarizes the difference in response that is observed when the cradle system and concrete mass system are subjected to the same shock acceleration load. The excitation curve shows the triangular acceleration pulse that was applied to the base of both systems in the vertical direction as the input load. The fuel assembly center of gravity (FA CG) - Cradle curve shows the response acceleration of the centrally located detailed fuel assembly center of gravity, while the FA CG - Concrete shows the response of the CG of the fuel assembly in the concrete system case. The two response curves are filtered with a Butterworth filter to eliminate 
frequency content above $100 \mathrm{~Hz}$. The initial non-zero acceleration in both response curves is a numerical artifact caused by the filtering and an initial imbalance of forces associated with the gravity load.

The spurious behavior is resolved by one millisecond and has no significant effect on the model results. The filtering operation amplifies the apparent influence of the initial imbalance of forces, but it allows for a meaningful comparison of the peak acceleration response values. In this case, an excitation pulse with a peak of $6.4 \mathrm{~m} / \mathrm{s}^{2}$ caused a peak response of $31.4 \mathrm{~m} / \mathrm{s}^{2}$ in the fuel assembly of the cradle system and a peak response of only $4.9 \mathrm{~m} / \mathrm{s}^{2}$ in the fuel assembly of the concrete system. So, the cask and cradle system effectively amplifies the response of the fuel (relative to the input) while the concrete system reduces the fuel assembly response (relative to the input). This analysis further demonstrates the loads transmitted through the cask/cradle structure, and shows that the concrete monolith option could potentially underrepresent the loads on the fuel assembly.

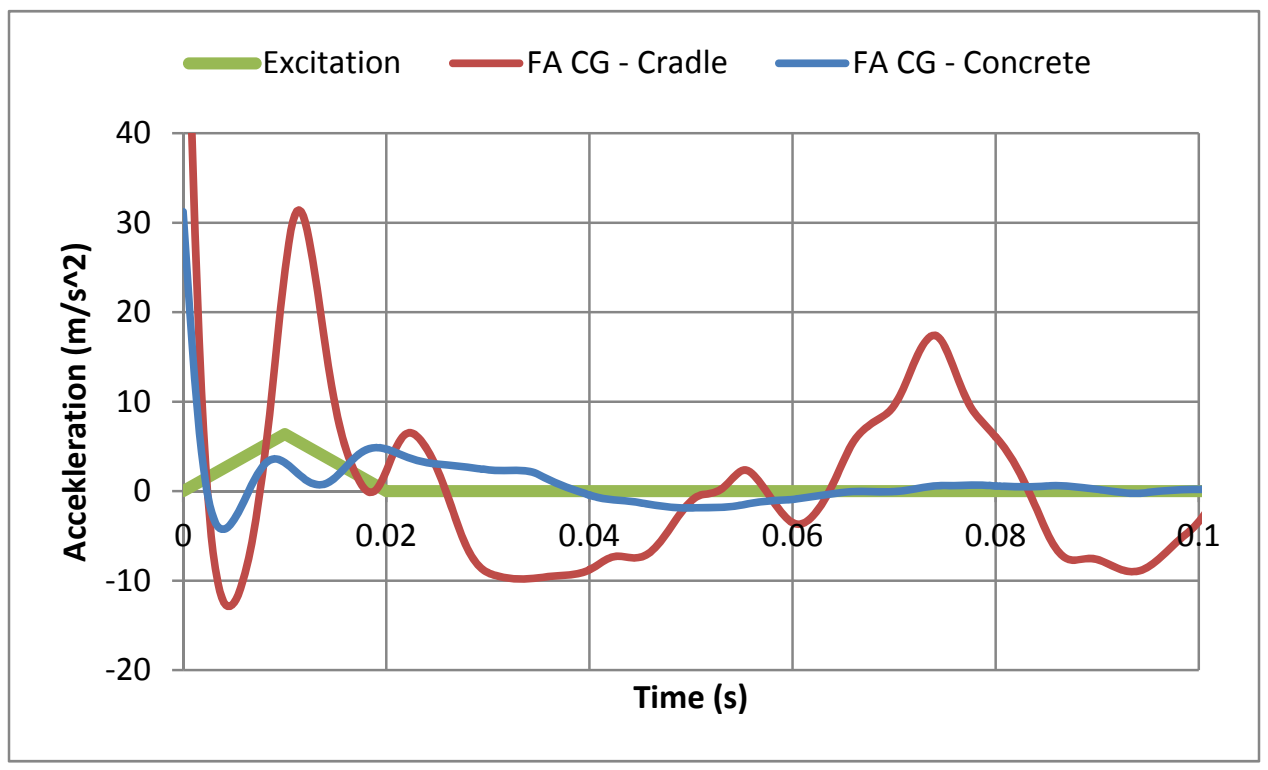

Figure 4-9 - Nonlinear Analysis of Load Transference

\subsection{Analysis Summary}

Using a number of analytical approaches, the feasibility of using a concrete mass system in the test plan is explored. In every analysis, a significant difference is found between the dynamic characteristics of the concrete block monolith and a realistic cask/cradle system. In the comparison of effective vertical stiffness, the concrete block is found to be 3-10 times stiffer than the realistic cask/cradle system.

In the frequency domain analyses, the concrete block was found to have fundamental vibration modes with a much higher frequency than the cask/cradle, which notably had vibration modes within the range of interest for fuel assemblies while the concrete block did not. The frequency response spectra showed that cask/cradle amplified the response of the cask between $35-100 \mathrm{~Hz}$, while the concrete block attenuated the response in the range of 1-100 Hz. Comparatively, the 
response of the realistic cask/cradle system is more than an order of magnitude higher than the concrete block throughout the range of 1-100 Hz.

In the time domain analyses, simplistic models of the whole railcar system predicted a stronger response for the cask/cradle system than the concrete block system. A more detailed mechanical shock response analysis was made using the concrete block and cask/cradle models used in the first analyses and a used fuel assembly model that was developed for the UFDC Structural Uncertainty task (Klymyshyn 2013b). The results show that the loads transmitted through the system to the fuel assembly was lower in the concrete monolith case and significantly higher in the detailed cask/cradle case.

These analyses support the conclusion that the composition of the cask/cradle structure has a strong influence on the response of the fuel assembly. The basket support option selected by the test plan must ensure that the loads transferred from the railcar to the basket are both conservative and similar to a realistic cask/cradle system. This suggests that further qualification of the cost-effective cast-in-place concrete block concept is necessary prior to final selection. It would be necessary to use computer simulation modeling to ensure that such a concrete monolith's response to shock and vibration forces at the frequencies of interest would be similar to the response of the structure of a metal transportation cask. Therefore, the surrogate mass will need to be engineered to best represent the expected response from an actual rail cask.

In addition, the results of this analysis series indicate that any proposed test platform needs to be evaluated in the structural dynamic realm as was presented here. Modal analysis, frequency response analysis, and time domain shock analysis are needed to characterize the proposed test platform. Even when using an actual cask/cradle system, this analysis and characterization is necessary to interpret the results of testing. Because the cask/cradle composition affects the transmission of loads to the fuel, we have to be able to identify the characteristics of the test system so the results can be extended to other cask/cradle designs. Variations in cask/cradle design will likely affect the loads transmitted to the fuel, so any one test series using a single cask/cradle configuration is not sufficient to characterize the loads across all possible configurations. At a minimum, any test system needs to be characterized and documented for model benchmarking prior to be used for future comparisons against any other systems. A smaller cask system like the NLI 10/24 cask is expected to demonstrate a different dynamic response than a larger cask system, leading to a difference in loads on the fuel. Whichever cask system is selected, it should be fully characterized with analysis so the key results can be generalized.

The two existing cask/cradle systems considered in this options report, the NLI 10/24 and the TN-32, are expected to have significantly different responses. However, either one would be useful as long as sufficient system characterization is performed. For example, modal analysis could be performed and an experimental validation of the modal analysis model could be conducted in the shop, prior to over-rail-testing. Ideally, both cask/cradle systems would be evaluated and used in testing, but if testing is limited to one or the other, the test campaign could fully characterize the one system used so the results can be interpreted in context.

As a specific example, the cladding strains recorded using the NLI 10/24 cask are not expected to match the cladding strains recorded using the $\mathrm{TN}-32$ system, even if all the variables such as 
track surface and speed are identical. The different mass and stiffness of the cask/cradle structures are expected to cause a difference in the response. Modal analysis and frequency response analysis could be used to characterize and compare the two systems to determine which one might impose stronger loads on the fuel, but even so, that would not guarantee that testing bounded all possible cask/cradle designs. Verification of the analytical approach would then permit extension of the methodology to study other potential designs and transport systems.

The option of creating a mock up cask/cradle system for use in testing adds complexity but may be more useful for testing different rail transport systems. A mockup cask/cradle system could be specifically designed to have structures that could be altered to vary its dynamic properties. For example, the four corner posts could be adjustable to alter the vibration mode frequencies and the frequency response spectrum. In this manner, the test campaign could establish the response for a number of different cask designs and configurations. A fixed design like the TN-32 or NLI 10/24 would only offer one fundamental response. It could be altered by adding or subtracting mass, but no fundamental structural behavior in the support system could be changed. A purpose-built cask/cradle system would offer more flexibility in exploring the largest range of response. 


\section{RAIL SHOCK AND VIBRATION ANALYSIS AND TESTING PROGRAM}

The Rail S\&V Test Program is supported by, or enhanced by, analysis and testing options. This program follows a recent series of tests conducted at SNL in which a surrogate PWR fuel assembly was subjected to simulated truck transportation shock and vibration on a vibrationtable test machine and then to shock and vibration in an over-the-road truck test. The results of the SNL vibration-table tests are reported in McConnel1 et al. (2013), and results of the over-theroad tests are reported in McConnell et al. (2014). In a recent literature review, Maheras et al. (2013) identified the historic record of transportation shock and vibration analyses and testing that has been conducted to support assessments of the safety of transporting used nuclear fuel.

It is generally believed that over-the-road truck tests would present shock and vibration loads on simulated fuel rods that exceed those that would be expected for rail transportation, except possibly the loads that would result from buff and draft forces and coupling shocks. However, there have been no definitive tests under conditions of rail transportation that can be identified that would confirm the subjective consensus. Furthermore, there are no definitive data that can be used to confirm that the railcar/train/cask-system structures do not amplify normal rail shock and vibration loads that fuel assemblies would experience. Additionally, the truck casks are smaller in mass than the larger cask systems that can be carried by rail (approximately 25 tons for truck casks versus approximately 125 tons for rail casks), which makes it difficult to make a direct comparison between truck and rail shock and vibration data. The analysis and testing program described in this document is designed to close the gaps in information so that there is a strong basis for ensuring the integrity of HBU and long-term stored fuel is maintained during normal rail transportation. That would enhance confidence that the fuel can be safely shipped from commercial nuclear power plant sites to interim storage and/or disposal sites. The following sections discuss the proposed rail shock and vibration testing options including the possibility of shaker table tests for both rail and truck environments.

\subsection{Rail Shock and Vibration Testing}

This section presents the railcar testing options for the proposed shock and vibration testing. Five railcar options, four cask options, four transport cradle options, and four model fuel assembly options have been proposed for use in the rail operational tests for the proposed rail shock and vibration testing. This section describes the railcar, railcar truck (wheel), cask, cradle, and surrogate fuel assembly options.

\subsubsection{Railcar Options}

Table 5-1 presents the five railcar options being considered for the shock and vibration testing. These options include varying truck designs with the overall objective of using a railcar and truck combination that is judged to be close to the AAR Standard S-2043 (AAR 2008) railcar requirements to best mirror the expected railcar configuration for future used nuclear fuel shipments. Railcar simulations have indicated that depressed-center cars (approximately $90 \mathrm{ft}$ long) with premium trucks or flatcars (approximately $60 \mathrm{ft}$ long) with premium trucks could 
meet the S-2043 standard. The casks that may be carried range in size from 25 to 160 tons with a maximum load size of about 17 feet long, 12 feet wide, and not to exceed 15 feet from the top of the rail. When a railcar is selected for shock and vibration testing, its railcar trucks are also preselected. However, Table 5-1 provides additional insight into the variability of railcar truck designs. If the Rail S\&V Program team determines testing with an alternate railcar truck configuration is required, TCRY has the facilities and capability of changing railcar trucks. Included in Table 5-1 are both flat and depressed-center cars.

Table 5-1. Railcar Options for Rail Shock and Vibration Test Program

\begin{tabular}{|c|c|c|}
\hline Option & Advantages & Disadvantages \\
\hline $\begin{array}{l}\text { Commercial } \\
\text { 8-axle depressed- } \\
\text { center car with } \\
\text { standard 3-piece } \\
\text { trucks } \\
\text { (See Figures 5-1 } \\
\text { and 5-2) }\end{array}$ & $\begin{array}{ll} & \text { Low payload center of gravity } \\
\text { - } & \text { Immediately available vs S-2043 } \\
\text { railcar }\end{array}$ & $\begin{array}{l}\text { - } \quad \text { Cost more than flatcar } \\
\text { Depressed-center car may not be used in } \\
\text { DOE fleet. } \\
\text { - Unlikely that 3-piece trucks will be used } \\
\text { on S-2043 railcars. }\end{array}$ \\
\hline $\begin{array}{l}\text { Commercial } 8 \text { axle } \\
\text { flatcar with } \\
\text { standard 3-piece } \\
\text { trucks } \\
\text { See Figures 5-3 } \\
\text { and 5-4 }\end{array}$ & $\begin{array}{ll}\text { - } & \text { Flatcars are likely for the DOE fleet. } \\
\text { - } & \text { Flatcars are available at low cost }\end{array}$ & $\begin{array}{l}\text { - High center of gravity. } \\
\text { - Unlikely that 3-piece trucks will be used } \\
\text { on S-2043 railcars }\end{array}$ \\
\hline $\begin{array}{l}\text { Commercial 8-axle } \\
\text { depressed-center } \\
\text { car with M-976 or } \\
\text { BX trucks } \\
\text { See Figures 5-5, } \\
\text { 5-6, 5-7, and 5-8. }\end{array}$ & $\begin{array}{l}\text { - } \quad \text { Low payload center of gravity } \\
\text { - } \quad \text { Immediately available vs S-2043 car } \\
\text { - } \quad \text { M-976 or BX trucks, which are likely } \\
\text { to be used on S-2043 railcars }\end{array}$ & $\begin{array}{l}\text { - } \quad \text { Cost more than flatcar } \\
\text { Depressed-center car may not be used in } \\
\text { DOE/MDO fleet. } \\
\text { - It may not be possible to change truck } \\
\text { type on an existing railcar. }\end{array}$ \\
\hline $\begin{array}{l}\text { Commercial 8-axle } \\
\text { flatcar with M-976 } \\
\text { or BX trucks } \\
\text { See Figures 5-5, 5- } \\
\text { 6, 5-7, and 5-8 }\end{array}$ & $\begin{array}{l}\text { - } \quad \text { Flatcars are likely for a DOE fleet } \\
\text { - Flatcars are available at low cost } \\
\text { M-976 or BX truck is likely to be used } \\
\text { on S-2043 railcars. }\end{array}$ & $\begin{array}{l}\text { - High center of gravity } \\
\text { - } \quad \text { It may not be possible to change truck } \\
\text { type on an existing railcar. }\end{array}$ \\
\hline $\begin{array}{l}\text { NLIX Railcar } \\
\text { See Figure 5-10 }\end{array}$ & $\begin{array}{l}\text { - Existing railcar designed to transport } \\
\text { the NLI 10/24 UNF rail cask. } \\
\text { - Possibly available for testing along } \\
\text { with the NLI 10/24 cask } \\
\text { - Recent transfer of ownership to } \\
\text { TCRY }\end{array}$ & $\begin{array}{l}\text { - } \quad \text { Railcar designed in 1970s } \\
\text { Currently "land locked" in Augusta, } \\
\text { Georgia railyard, and may not be } \\
\text { available for use } \\
\text { - } \quad \text { Railcar has not been moved in over } 30 \\
\text { years, and the railcar would need to be } \\
\text { refurbished or may not be useable. }\end{array}$ \\
\hline
\end{tabular}

A depressed-center 8-axle railcar would be similar to the railcar illustrated in Figure 5-1, which is a design developed by the Private Fuel Storage (PFS) project and which has undergone testing at the AAR TTCI in Pueblo, Colorado. Figure 5-2 illustrates the dimensions and general 
geometric configuration of a commercial depressed-center 8-axle railcar. Figures 5-3 and 5-4 illustrate the dimensions and general configuration of a commercial 8-axle flatcar.

One of the objectives of the Rail S\&V Test Program is to select a railcar that is representative of railcars that will be used for the actual transportation of used nuclear fuel when shipping campaigns begin. To support the selection of a railcar, computer modeling may be used to help inform a decision regarding the railcar type that is used in conducting the shock and vibration rail operational tests.

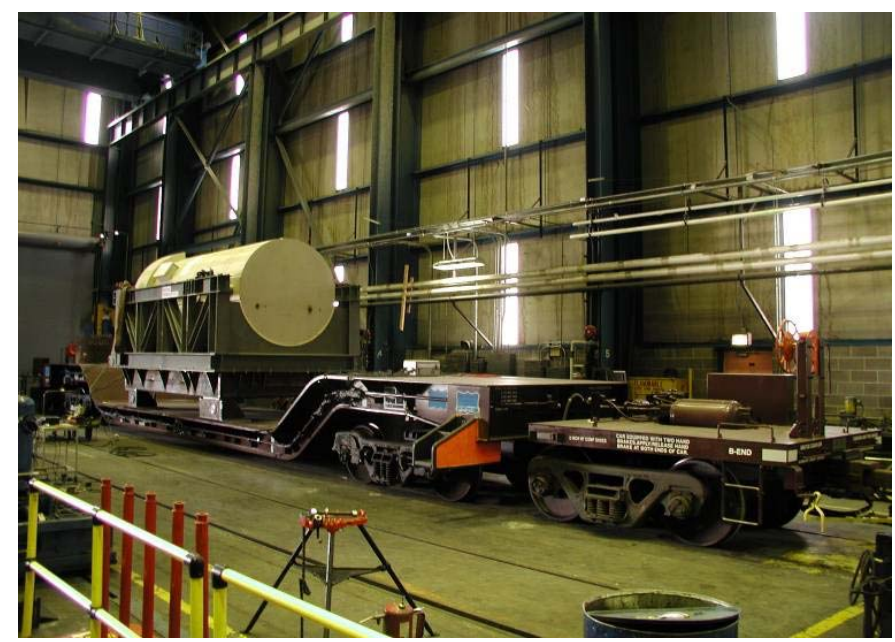

Figure 5-1. PFS Depressed-center 8-Axle Railcar

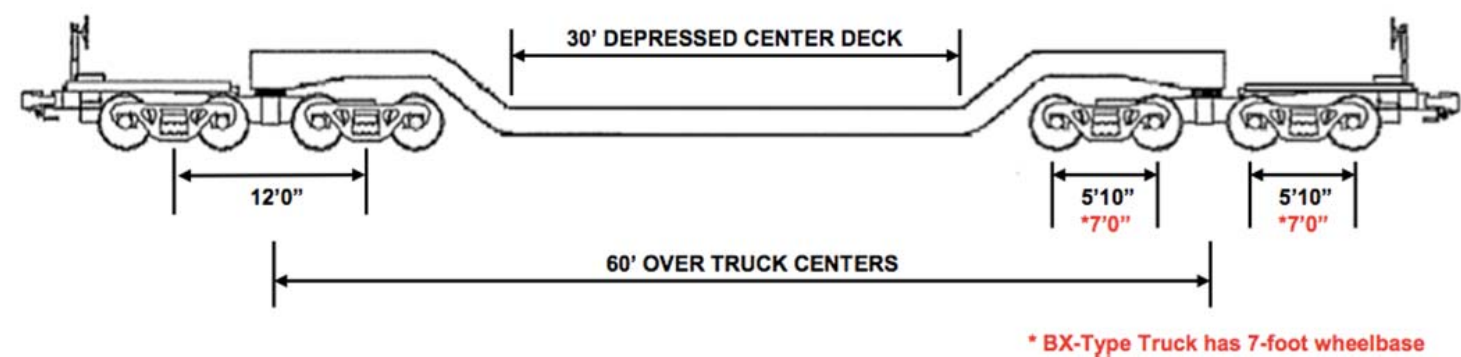

Figure 5-2. Dimensions and General Configuration of 8-Axle Depressed-center Railcar 


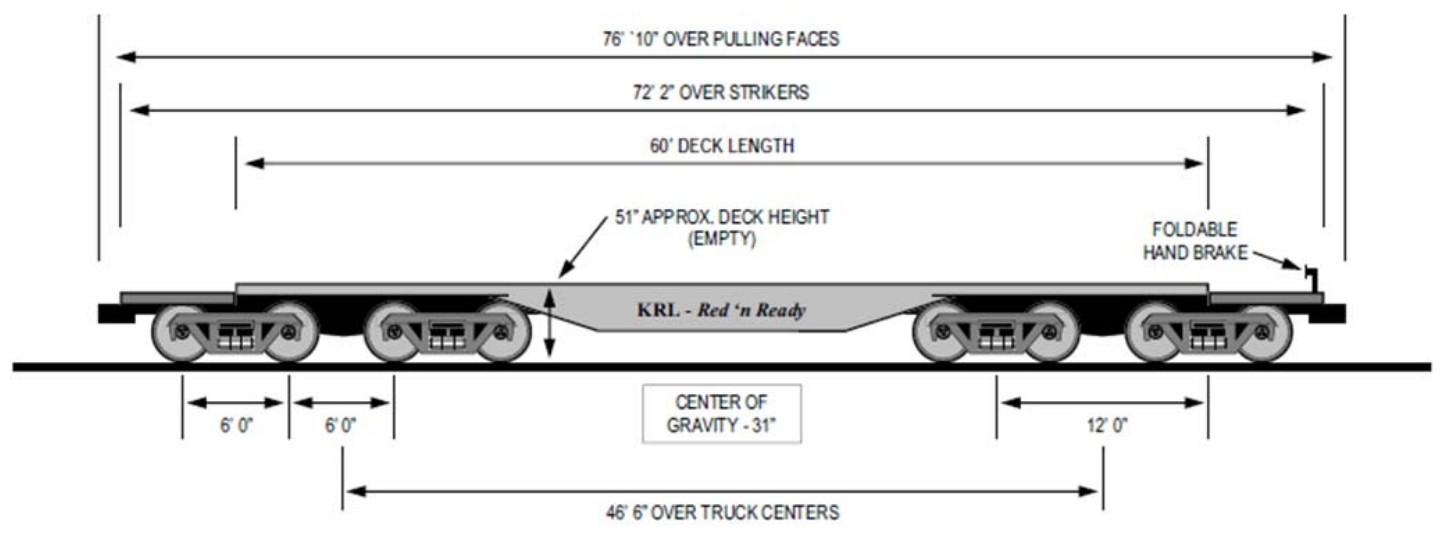

Figure 5-3. Dimensions and General Configuration of 8-Axle Flatcars

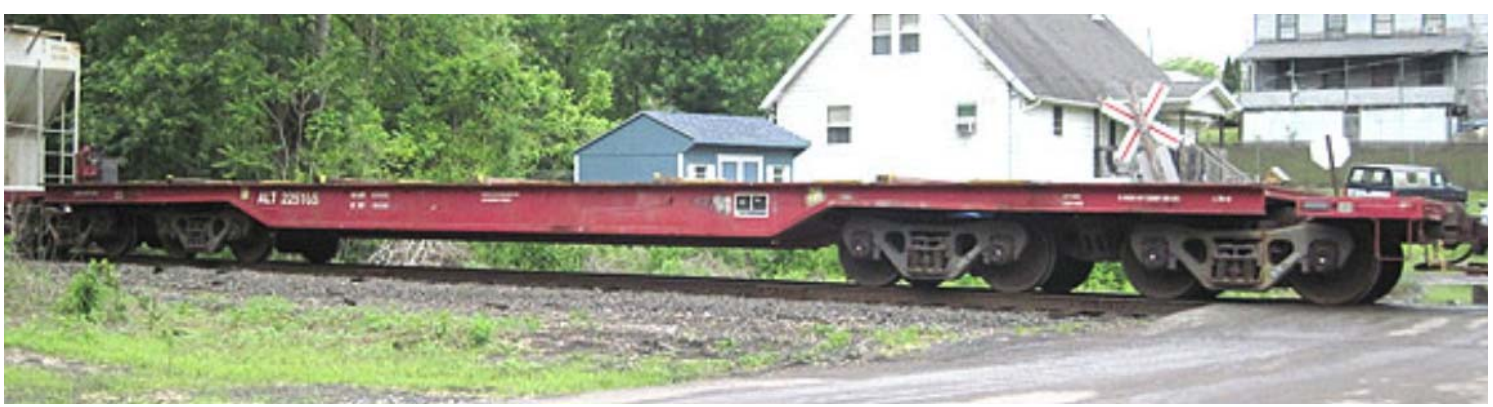

Figure 5-4. Commercial 8-Axle Flatcar

\subsubsection{Railcar Wheel Truck Options}

Figure 5-5 illustrates a conventional railcar wheel truck. Figures 5-6, 5-7, and 5-8 show the configurations of conventional 3-piece trucks, M-976 trucks, and BX-type trucks. Most railcars in service on U.S. railroads use conventional 3-piece trucks and it is likely that depressed-center and flatcars that would be available for lease for the Rail S\&V Test Program will come equipped with this kind of truck.

However, a report prepared for Booze-Allen-Hamilton by the Transportation Technology Center, Inc. (TTCI 2005) suggested that M-976 or BX-type wheel trucks could be used on railcars that meet the S-2043 standard for transporting casks containing high-level radioactive material. The TTCI suggestion regarding railcar trucks for railcars that transport UNF payloads was based on the performance of the various truck designs under conditions that could lead to derailments, and not based on the shock and vibration forces that the wheel truck would transmit into the railcar structure during normal transportation. If feasible, based on cost, the Rail S\&V Test Program may obtain M-976 or BX-Type wheel trucks and have these installed on the test railcar by TCRY. 


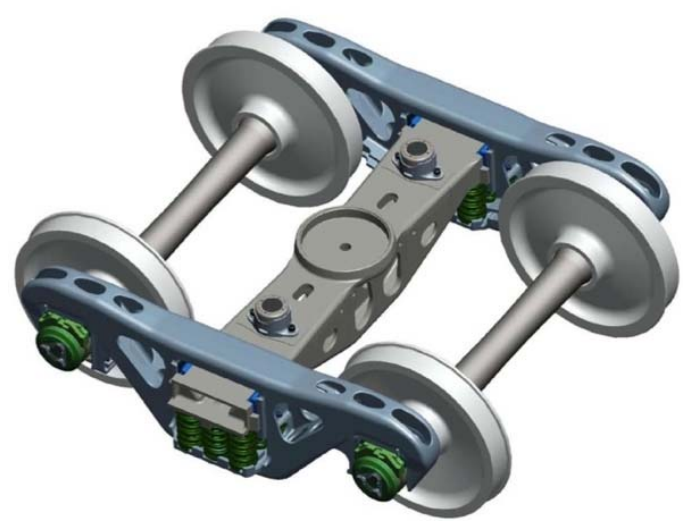

Figure 5-5. Railcar Wheel Truck

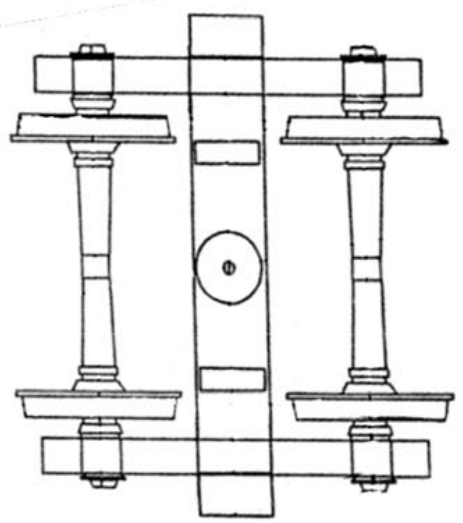

Figure 5-6. 3-piece Truck

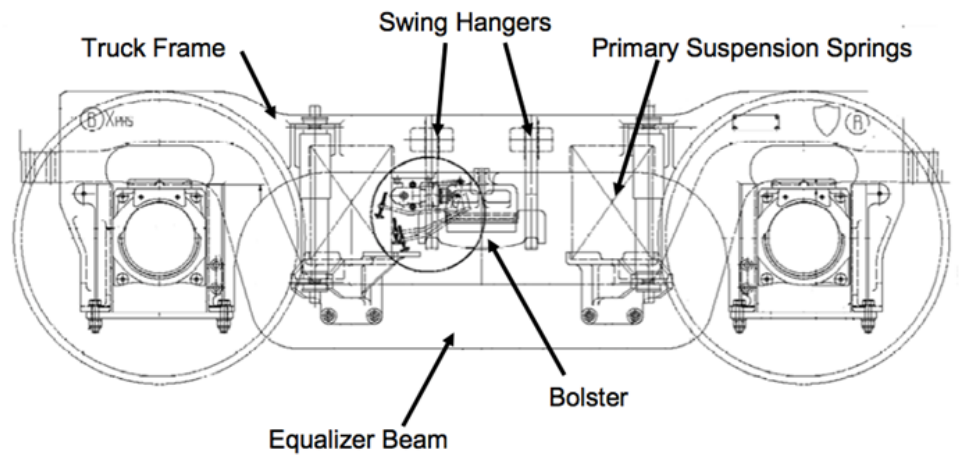

Figure 5-7. M976 Truck Design 


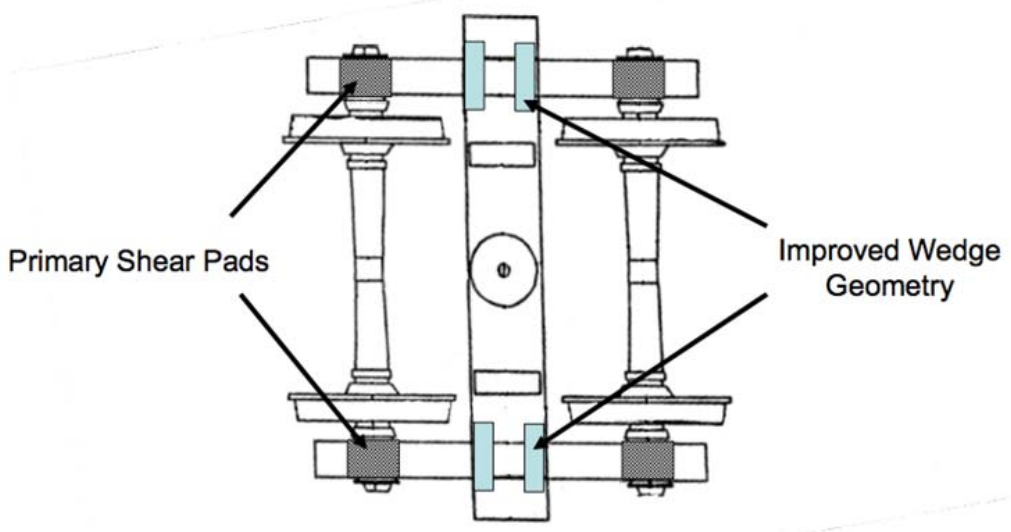

Figure 5-8. BX Truck

\subsubsection{Shipping Cask Options}

Table 5-2 presents the shipping casks options for the UNF shock and vibration rail testing program and discusses the advantages and disadvantages of each of the potential options. 
Table 5-2. Shipping Cask Options for Rail Shock and Vibration Test Program

\begin{tabular}{|c|c|c|}
\hline Option & Advantages & Disadvantages \\
\hline $\begin{array}{l}\text { AREVA TN-32 } \\
\text { Cask (cask not } \\
\text { designated for use } \\
\text { in the Industry } \\
\text { /DOE-sponsored } \\
\text { Dry Storage } \\
\text { Demonstration Test } \\
\text { Project) } \\
\text { (See Figure 5-9) }\end{array}$ & $\begin{array}{l}\text { - High-capacity state-of-the-art } \\
\text { commercial cask with fuel assembly } \\
\text { basket; planned application to NRC } \\
\text { for certification of the TN-32 design } \\
\text { to transport high-burnup UNF } \\
\text { Assumes cask would be made } \\
\text { available for testing at no cost to } \\
\text { DOE. } \\
\text { Cost to transport the cask to the } \\
\text { Richland, Washington may be paid by } \\
\text { the PNNL-directed thermal analysis } \\
\text { test verifications project. }\end{array}$ & $\begin{array}{l}\text { - Impact limiters not available. } \\
\text { - } \quad \text { Uncertain availability of transport cradle } \\
\text { - } \text { instrument-lead pass-throughs } \\
\text { - Instrumentation of basket must be limited } \\
\text { not to impact the value of the cask for } \\
\text { future use. } \\
\text { - } \quad \text { Cost of damage insurance for test program } \\
\text { - Cask must be returned to AREVA } \\
\text { following tests. } \\
\text { Cost to transport from the Pennsylvania } \\
\text { location to Richland, Washington, if not } \\
\text { paid by another project }\end{array}$ \\
\hline $\begin{array}{l}\text { AREVA TN-32 } \\
\text { Cask (cask } \\
\text { designated for use } \\
\text { in the } \\
\text { Industry/DOE } \\
\text { sponsored Dry } \\
\text { Storage } \\
\text { Demonstration Test } \\
\text { Program) (See } \\
\text { Figure 5-9) }\end{array}$ & $\begin{array}{l}\text { - High-capacity state-of-the-art } \\
\text { commercial cask with basket; planned } \\
\text { application to NRC for certification to } \\
\text { transport high-burnup UNF. Expected } \\
\text { to include transport cradle. } \\
\text { - } \quad \text { Plan is to use the cask to transport } \\
\text { HBU fuel to INL to conclude the Dry } \\
\text { Storage Demonstration Project. } \\
\text { - Cost for use of the cask for S\&V } \\
\text { testing will be covered by the } \\
\text { DOE/Industry Dry Storage } \\
\text { Demonstration Project's budget. }\end{array}$ & $\begin{array}{l}\text { - } \quad \text { Impact limiters are not available. } \\
\text { - } \quad \text { instrument-lead pass-throughs } \\
\text { - Transportation shock and vibration test use } \\
\text { including long-haul testing over varying } \\
\text { routes and instrumentation of basket must } \\
\text { not risk compromising use of the cask in } \\
\text { the Dry Storage Demonstration Project. } \\
\text { - Cost of damage insurance for test program } \\
\text { - } \quad \text { Not available for designed tests using } \\
\text { engineered and defined test facilities and } \\
\text { conditions such as those at TTCI or TCRY } \\
\text { Cost of extended long-haul transportation } \\
\text { to obtain representative normal rail } \\
\text { conditions }\end{array}$ \\
\hline $\begin{array}{l}\text { NLI 10/24 Cask } \\
\text { (See Figure 5-10) }\end{array}$ & $\begin{array}{l}\text { - 100-ton UNF rail transportation cask } \\
\text { body with impact limiters } \\
\text { - Cask design was formerly certified by } \\
\text { NRC for transport of UNF. } \\
\text { - Ownership recently transferred to } \\
\text { TCRY }\end{array}$ & $\begin{array}{l}\text { Not a state-of-the-art UNF transportation } \\
\text { cask. Unlikely expired NRC certification } \\
\text { could be renewed. } \\
\text { - Fuel assembly basket would need to be } \\
\text { designed and fabricated. } \\
\text { - Transport cradle would need to be } \\
\text { designed and fabricated if the NLIX railcar } \\
\text { cannot be used. } \\
\text { - Cask must be recovered from "land } \\
\text { locked" status on railcars in Augusta, } \\
\text { Georgia railyard. } \\
\text { - Negative optics-not a modern rail cask. }\end{array}$ \\
\hline
\end{tabular}


Table 5-2. (contd.)

\begin{tabular}{|c|c|c|}
\hline Option & Advantages & Disadvantages \\
\hline Surrogate Mass & $\begin{array}{l}\text { - } \\
\text { - Can be designed and constructed to } \\
\text { simulate weight and weight- } \\
\text { distribution of a large modern } \\
\text { commercial shipping cask. Also, it is } \\
\text { likely the surrogate mass with an } \\
\text { internal basket structure could be } \\
\text { designed to simulate the response of a } \\
\text { large shipping cask containing UNF in } \\
\text { canisters. } \\
\text { - Could be constructed at an industrial } \\
\text { location such as TCRY. } \\
\text { S-2043 allows the use of a simulated } \\
\text { or surrogate mass for testing a railcar. }\end{array}$ & $\begin{array}{l}\text { - } \\
\text { - } \\
\text { Affordable cost mass would probably be } \\
\text { rebar-reinforced cast concrete with limited } \\
\text { space for a fuel assembly basket structure. } \\
\text { The simulated cask and simulated basket } \\
\text { structure would need to be designed and } \\
\text { demonstrated to provide responses to S\&V } \\
\text { forces that simulated the responses for cask } \\
\text { bodies and baskets in state-of-the-art } \\
\text { storage/transport canisters or transportation } \\
\text { casks. }\end{array}$ \\
\hline \multicolumn{3}{|c|}{$\begin{array}{l}\text { DOE = U.S. Department of Energy, HBU = high burnup, INL = Idaho National Laboratory, NRC = U.S. Nuclear } \\
\text { Regulatory Commission, PNNL = Pacific Northwest National Laboratory, S\&V = shock and vibration, TCRY = Tri- } \\
\text { City Railroad, TTCI = Transportation Technology Center, Inc., UNF = used nuclear fuel }\end{array}$} \\
\hline
\end{tabular}

Figure 5-9 shows TN-32 casks that are being used to store used nuclear fuel at a nuclear power plant site. The TN-32 cask design has not been certified by the U.S. Nuclear Regulatory Commission (NRC) for transportation of UNF but is similar in design to the TN-40 cask, which the NRC has certified (Certificate No. USA/9313/B(U)F-96).

AREVA, Inc. North America has proposed to provide one of two available TN-32 casks for use by DOE to conduct rail shock and vibration tests. DOE and AREVA have also discussed installing instrumented surrogate fuel assemblies in the second cask to record shock and vibration when the cask is shipped by rail from its current location in Pennsylvania to a facility in North Carolina. The second TN-32 cask will be used in the DOE/Industry Dry Fuel Storage Demonstration Project that will be conducted at the Dominion Power North Anna nuclear plant site.

Impact limiters, which can cost more than $\$ 1$ million for a set, have not been constructed for the TN-32 casks and it is assumed that none would be provided for use in either of the possible rail shock and vibration testing programs. S\&V tests that used a TN-32 cask could provide data useful in obtaining certification of the TN-32 cask to transport high-burnup UNF. The NRC certification will be required for shipping the high burnup UNF loaded into the cask for the Dry Storage Demonstration Project to a fuel examination facility following the dry storage test period. The baskets inside TN-32 casks are designed to contain 32 PWR fuel assemblies.

Figure 5-10 shows a NLI 10/24 rail shipping cask on a dedicated NLIX railcar. The NLI 10/24 casks and railcars are owned by TCRY in Richland, Washington. TCRY plans to recover the casks from a "land locked" rail siding near Augusta, Georgia and ship them, possibly on the dedicated NLIX railcars, to its railyard during the last quarter of 2014. 


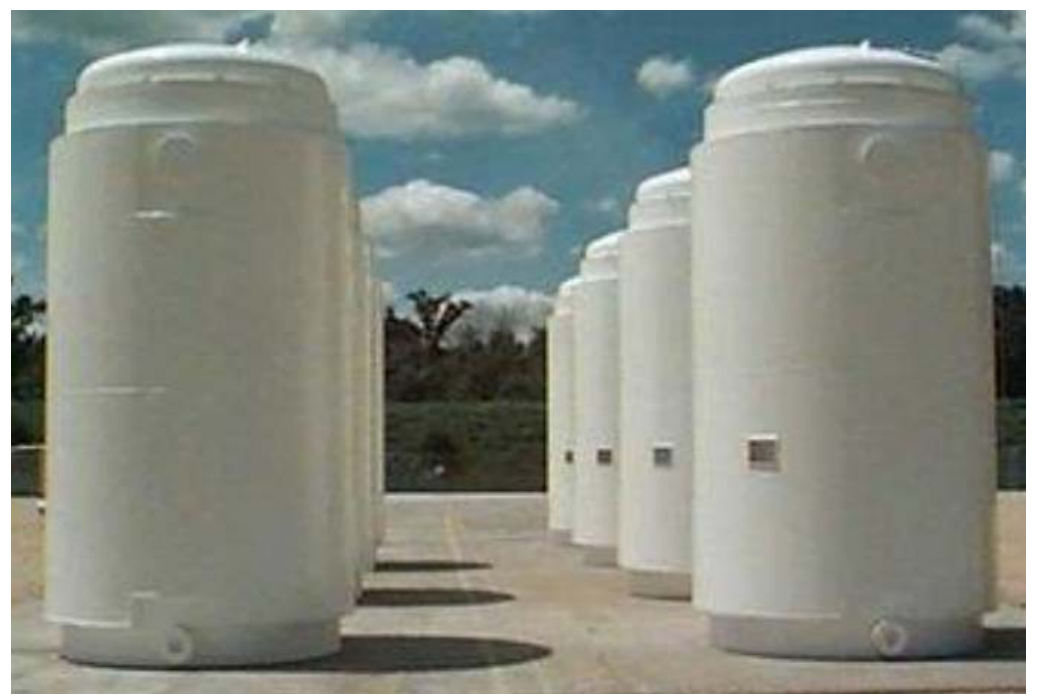

Figure 5-9. TN-32 Casks

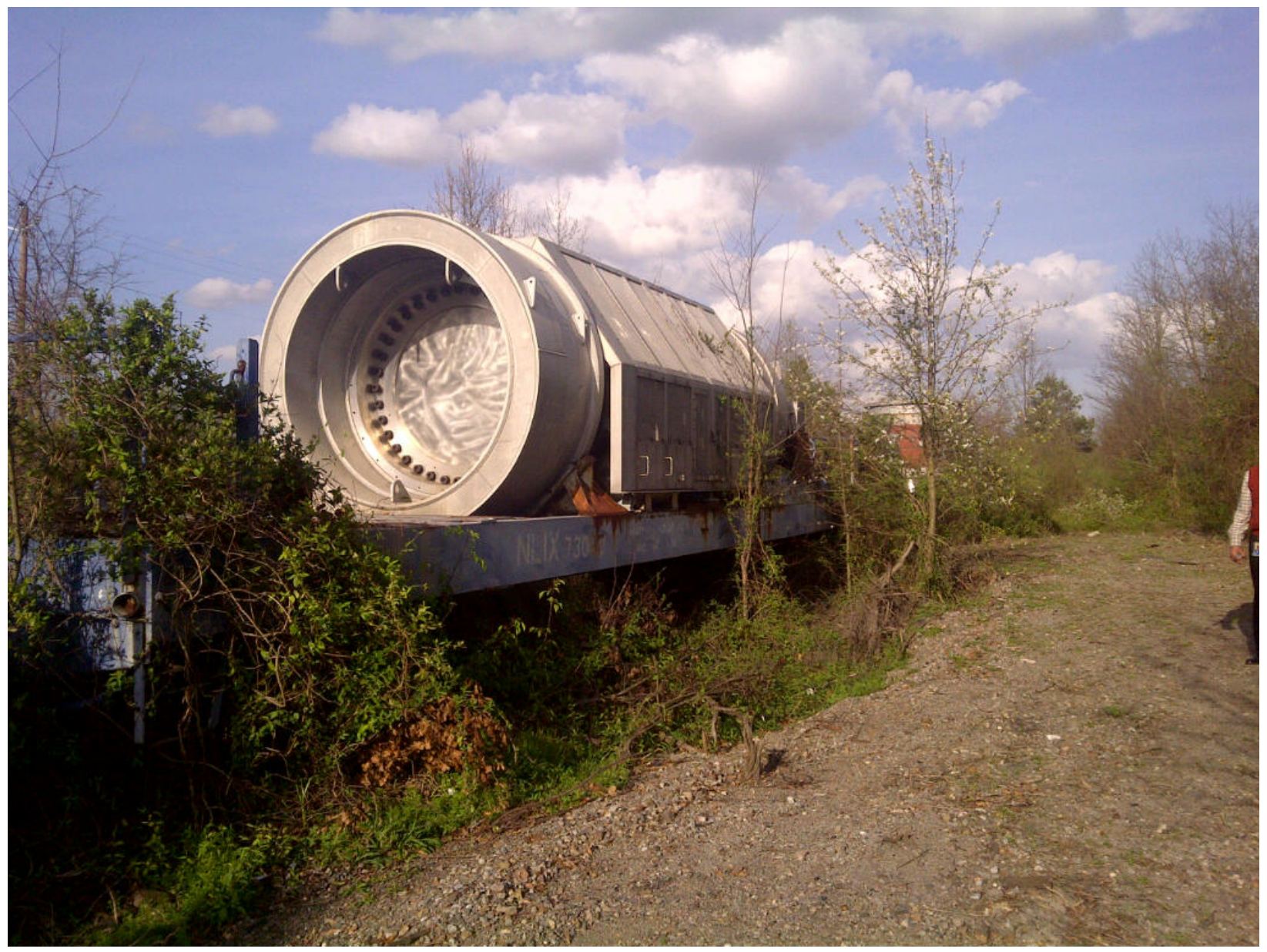

Figure 5-10. NLI 10/24 Rail Cask 
The NLI 10/24 cask, which would weigh approximately 100 tons when loaded with fuel assemblies, was designed and constructed by NL Industries in the 1970s for use to transport 10 PWR or 24 boiling water (BWR) fuel assemblies from commercial nuclear power plants to the Allied General Nuclear Services (AGNS) Barnwell Nuclear Fuels Reprocessing Plant (BNFP) that was under construction at the time in Barnwell, South Carolina.

One model of the cask was fully constructed including impact limiters. This cask is shown in the foreground of the photograph. The second, partially constructed model can also be seen in the background. The PWR basket for the fully constructed cask, which contained a significant amount of metallic silver, was removed and disassembled to remove silver, which was sold. Consequently, the cask does not have a basket. If the NLI 10/24 cask was chosen for testing, as a result of the TCRY ownership, the DOE would not have any disposal liability (for lead and depleted uranium) at the completion of the shock and vibration testing.

It is unlikely that NRC would renew the expired certificate of compliance for the NLI 10/24 cask. The cask and its NLIX railcar may be available for use in the proposed rail shock and vibration testing program.

Figure 5-11 is a schematic illustration of a postulated rebar-reinforced, 12-ft high by 12-ft wide by $18-\mathrm{ft}$ long concrete monolith that could be formed and used as a surrogate to represent the size, dimensions, weight, and rigidity of a large rail cask. The weight of the block represented by the illustration would be about 320,000 lb, approximately the weight of the NAC

MAGNATRAN cask, which is the largest of state-of-the-art industry-designed rail casks.

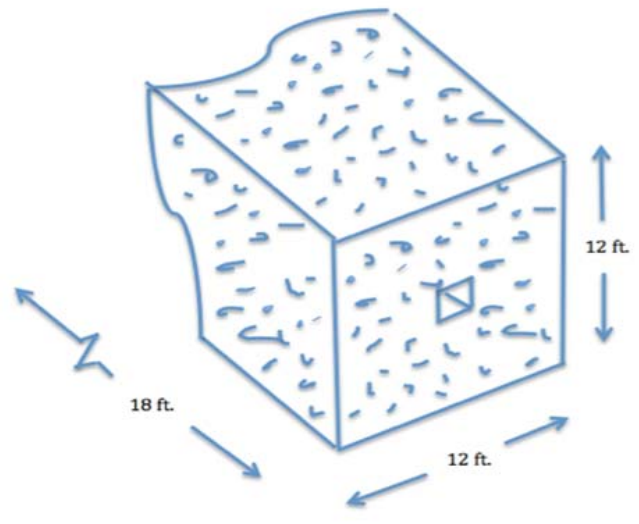

Surrogate Cask (mass) - Concrete Block $-320,000 \mathrm{lb}$

Figure 5-11. Surrogate Cask Mass

Other approaches for producing a cask-simulation concrete monolith include pouring concrete inside a large corrugated steel culvert pipe. A square, rectangular, or round pipe or cylinder, around which the concrete would be poured, could be used to provide the cavity for placement of surrogate fuel assemblies in the center of the massive block. 
It would be necessary to use computer simulation modeling to ensure that a concrete monolith's response to shock and vibration forces at the frequencies of interest would be similar to the response of the structure of a metal transportation cask.

One of the key advantages for using a surrogate mass such as that described would be its low cost. However, to get the desired response from the shock and vibration testing the surrogate mass will need to be engineered to best represent the expected response from an actual rail cask. In addition, the S-2043 standard (AAR 2003) allows the use of a surrogate mass for railcar testing.

\subsubsection{Transport Cradle Options}

Table 5-3 presents the proposed options for the transport cradle to be used in support of the UNF rail shock and vibration testing. For on-the-rail tests it will be necessary to support and tie down the cask or simulated cask mass that is loaded onto the railcar. The supports and tie downs could be simple, composed of the railcar deck and shoring that are attached to the deck and cable/chain restraints that attached to the railcar and the cask or mass. However, simple supports and restraints of this type will not be acceptable for tying down a TN-32 cask to the railcar, and would not be needed for the NLI 10/24 cask on its NLIX railcar. If a TN-32 cask was loaded onto a railcar and tied down with shoring and cables the outer body of the cask would likely sustain damage because the railcar would impart forces to the cask body in a manner that would differ from that intended by the cask's designer. Consequently, a transport cradle will be needed if the TN-32 cask is used in the test program. The transport cradle would likely be similar in design to the cradle shown in Figure 5-12, which was used to transport Three Mile Island Fuel (TMI) Debris Casks on railcars. AREVA has a transport cradle available for shipping the TN-32B for the demonstration project.

A transport cradle can be seen in the artist's illustration of a cask on its transport cradle presented in Figure 5-13.

Table 5-3. Transport Cradle Options for Rail Shock and Vibration Testing Program

\begin{tabular}{|c|c|c|}
\hline Option & Advantages & Disadvantages \\
\hline $\begin{array}{l}\text { AREVA TN-32 } \\
\text { Transport Cradle }\end{array}$ & $\begin{array}{l}\text { - Transport cradle would be designed } \\
\text { and fabricated by cask vendor. The } \\
\text { cradle would be for transporting the }\end{array}$ & - $\quad$ Time and cost to obtain cradle. \\
\hline $\begin{array}{l}\text { AREVA design } \\
\text { similar to cradle } \\
\text { illustrated in } \\
\text { Figure } 5-12\end{array}$ & TN-32 cask on a railcar. & \\
\hline $\begin{array}{l}\text { Transport Cradle } \\
\text { Replica } \\
\text { (only for surrogate } \\
\text { mass) - See } \\
\text { Figure } 5 \text {-13 }\end{array}$ & $\begin{array}{l}\text { - Response of a simulated cradle to } \\
\text { shock and vibration loads would be } \\
\text { similar to that of a cradle designed for } \\
\text { a shipping cask. }\end{array}$ & $\begin{array}{l}\text { - Not a cradle designed by a cask vendor for } \\
\text { a transportation cask. } \\
\text { Greater cost than that for a simple beam } \\
\text { structure. }\end{array}$ \\
\hline
\end{tabular}


Table 5-3. (contd.)

\begin{tabular}{|c|c|c|}
\hline Option & Advantages & Disadvantages \\
\hline $\begin{array}{l}\text { Simple Beam- } \\
\text { Structure Transport } \\
\text { Cradle (only for } \\
\text { surrogate mass) - } \\
\text { See Figure 5-14. }\end{array}$ & $\begin{array}{l}\text { Low cost and easily constructed. } \\
\text { Beam supports for a surrogate cask } \\
\text { mass would be located to transfer } \\
\text { loads from the simulated cask mass to } \\
\text { the railcar and from the railcar to the } \\
\text { mass at tiedown positions typical for } \\
\text { cask cradles. }\end{array}$ & $\begin{array}{l}\text { Response of a simple beam-structure } \\
\text { cradle to shock and vibration loads were } \\
\text { shown by modeling to differ from the } \\
\text { response of a cradle designed for use in } \\
\text { transporting a large shipping cask. }\end{array}$ \\
\hline $\begin{array}{l}\text { No Cradle (only for } \\
\text { surrogate mass) - } \\
\text { Simulated cask } \\
\text { (surrogate mass) } \\
\text { tied down on } \\
\text { railcar deck. }\end{array}$ & $\begin{array}{ll}\text { - } & \text { No cost } \\
\text { - } & \text { No instrumentation }\end{array}$ & $\begin{array}{l}\text { - Non-representative transfer of loads } \\
\text { between the railcar and the cask mass } \\
\text { would distort S\&V responses of both. }\end{array}$ \\
\hline ck and & ion & \\
\hline
\end{tabular}

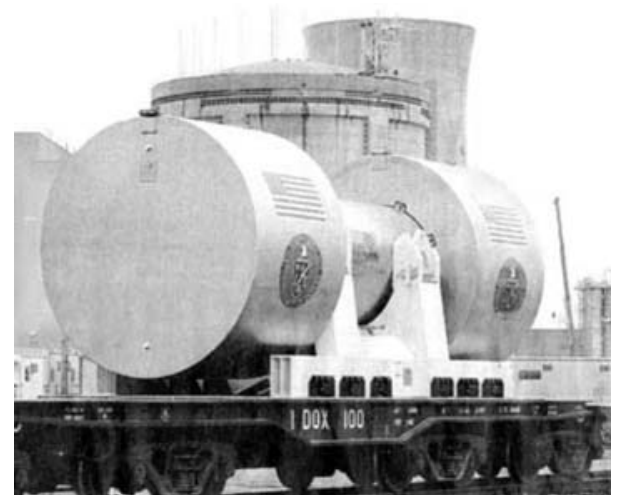

Figure 5-12. TMI Fuel Debris Shipping Cask on Transport Cradle on 8-Axle Railcar

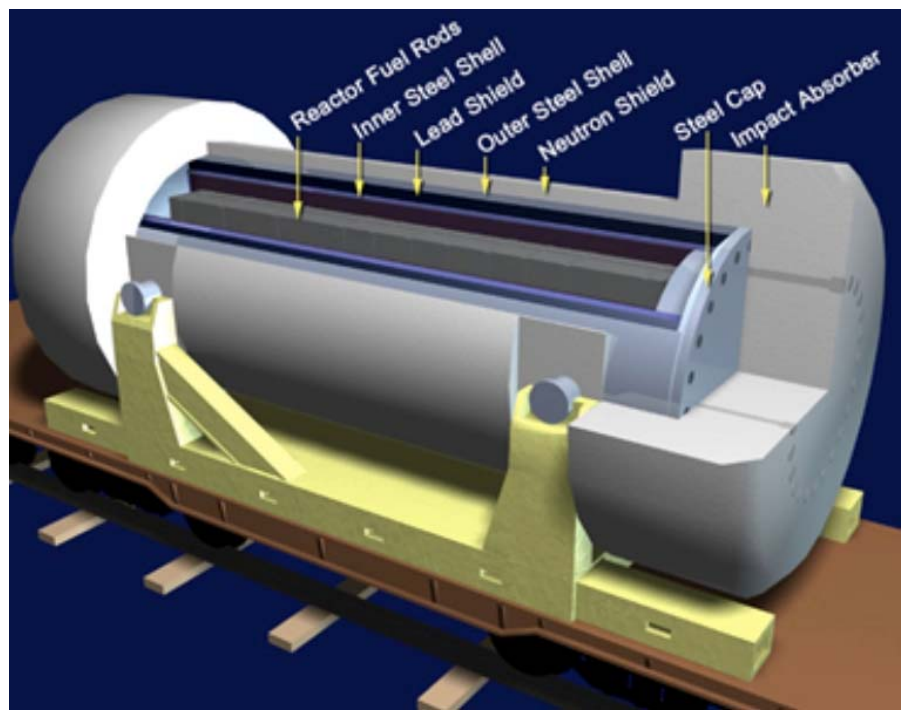

Figure 5-13. Artist's Illustration of Cask on Transport Cradle 
It would not be necessary to obtain a transport cradle if the NLI 10/24 Cask on its NLIX railcar is used in the Rail S\&V Test Program. For the S\&V tests the NLI 10/24 Cask would remain on its current support structure on the NLIX railcar. A cradle would need to be designed and constructed for the cask if the NLIX railcar could not be used in the tests.

If a surrogate mass is used to represent a rail cask, the support cradle can be a simple structure that would simulate the response of a rail cask's transport cradle in transmitting shock and vibration loads between the railcar and the mass. Figure 5-14 shows a simple 4-beam support used to lift a heavy load. The beam structure shown in the figure represents the simplicity, and inexpensive construction, of a structure that could be designed to support the surrogate cask mass on the test railcar.

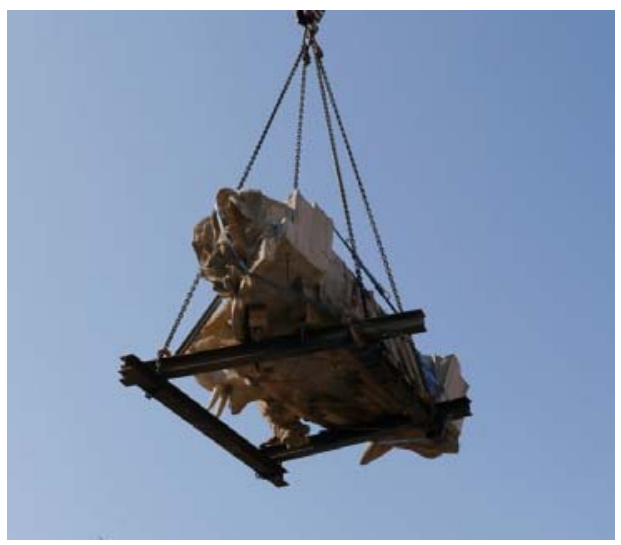

Figure 5-14. Simple Beam Structure Transport Cradle

Another example of a simple and relatively inexpensive support structure for a large, heavy load is shown in Figure 5-15.

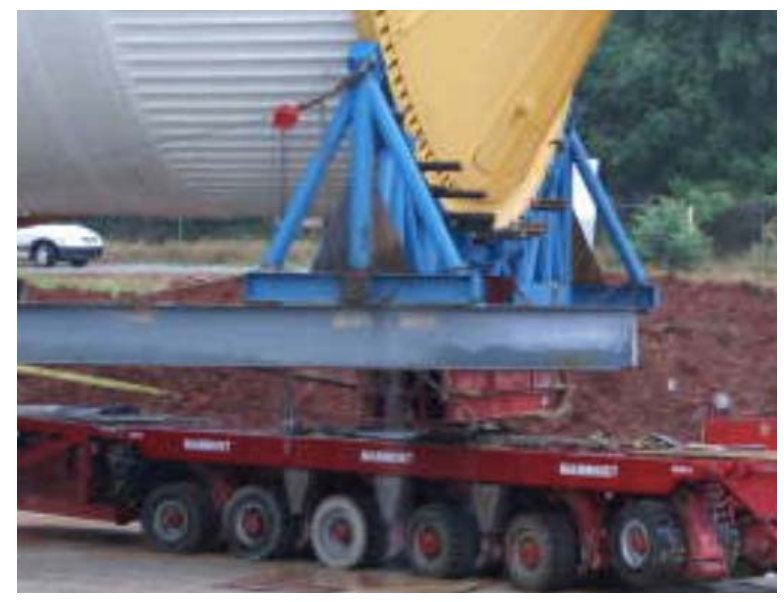

Figure 5-15. Simple Support Structure for Large, Heavy Load

The alternative of tying down the surrogate mass to the deck of the railcar and using shoring to prevent lateral and longitudinal movement could be used. However, the transfer of shock and 
vibration forces between the railcar and the simulated cask would not be representative of the transfer of forces between these two structures through a transport cradle.

\subsubsection{Surrogate Fuel Assembly Options}

Table 5-5 presents a summary of the surrogate fuel assembly options for the rail shock and vibration testing. Because using irradiated nuclear fuel assemblies will not be feasible for the shock and vibration test program, it will be necessary to use surrogate assemblies. The first surrogate fuel assembly shown in Table 5-5 is also presented in Figure 5-16 and has been used by SNL in shaker-table tests and in over-the-road truck tests to measure strains and accelerations of the simulated fuel rods resulting from simulated and real transportation shock and vibration forces. The SNL assembly, with the strain and accelerometer devices that are already installed, will also be used in the planned rail shock and vibration test program. The structural characteristics of the SNL assembly are both similar to and different from those of high burnup nuclear fuel.

The structural characteristics of the SNL assembly that are similar include:

- the weight of the assembly

- placement of flow control grids along the length of the assembly

- guide tubes that connect the assembly's top and bottom end fittings

- weight of fuel rods, fuel rods that have Zircaloy-4 cladding that surrounds simulated fuel

- $\quad$ simulated fuel that has approximately the same density as $\mathrm{UO}_{2}$ fuel pellets

- a 17X17 rod configuration, which is representative of state-of-the-art PWR fuel assemblies.

The structural characteristics of the SNL assembly that are different include the following:

- The fuel rod cladding was not irradiated in a reactor and as a consequence has not been subjected to neutron radiation work hardening.

- The assembly does not have precipitated zirconium hydride platelets dispersed in its structure.

- The assembly has not been thinned by surface oxidation.

- The assembly has not been distorted by interactions with fuel pellets.

- The fuel rods do not have internal gas pressure. $\mathrm{UO}_{2}$ fuel pellets are simulated with an elemental lead rod that is undivided over its full length.

- To make it possible to insert the lead rod into the cladding, it was necessary for the diameter of this rod to be slightly less than the inside diameter of the cladding. 
Table 5-4. Surrogate Fuel Assembly Options for Rail Shock and Vibration Testing Program

\begin{tabular}{|c|c|c|}
\hline Option & Advantages & Disadvantages \\
\hline $\begin{array}{l}\text { SNL- simulated } \\
\text { PWR fuel assembly } \\
\text { (instrumented) } \\
\text { See Figure 5-16 }\end{array}$ & $\begin{array}{l}\text { - Available surrogate } 17 \mathrm{X} 17 \text { fuel } \\
\text { assembly with installed } \\
\text { instrumentation. }\end{array}$ & $\begin{array}{l}\text { Lead-rod filled cladding in the SNL } \\
\text { assembly is not representative of fuel- } \\
\text { pellet filled cladding in commercial PWR } \\
\text { HBU fuel assemblies. } \\
\text { - Having only one surrogate fuel assembly } \\
\text { does not provide diversity that is desirable } \\
\text { for validating computer simulation } \\
\text { methods. }\end{array}$ \\
\hline $\begin{array}{l}\text { AREVA model } \\
\text { PWR fuel assembly } \\
\text { (instrumented) to } \\
\text { be provided by } \\
\text { AREVA }\end{array}$ & $\begin{array}{l}\text { - AREVA assembly characteristics } \\
\text { were not available at the time this } \\
\text { report was prepared. } \\
\text { Testing using a collection of different } \\
\text { surrogate fuel assemblies will provide } \\
\text { experimental data to support a more } \\
\text { robust validation of computer } \\
\text { simulation methods. }\end{array}$ & $\begin{array}{l}\text { - Instrumentation of multiple fuel assemblies } \\
\text { - } \text { will present challenges } \\
\text { - } \quad \text { Ast of damage insurance } \\
\text { Assembly will be returned to AREVA. }\end{array}$ \\
\hline $\begin{array}{l}\text { AREVA surrogate } \\
\text { PWR fuel } \\
\text { assemblies (not } \\
\text { instrumented) to be } \\
\text { provided by } \\
\text { AREVA }\end{array}$ & $\begin{array}{l}\text { For tests that involve a cask with a } \\
\text { basket (e.g., TN-32 or NLI 10/24 } \\
\text { casks) use of surrogate fuel } \\
\text { assemblies to fill the basket cells that } \\
\text { do not contain instrumented fuel } \\
\text { assemblies will improve the } \\
\text { simulation of the response of the } \\
\text { entire cask structure to S\&V force } \\
\text { inputs. }\end{array}$ & $\begin{array}{l}\text { - Cost of damage insurance for surrogate } \\
\text { fuel assemblies } \\
\text { - Time and care required to handle and } \\
\text { protect multiple high-value items }\end{array}$ \\
\hline $\begin{array}{l}\text { PNNL surrogate } \\
\text { PWR fuel assembly } \\
\text { masses (not } \\
\text { instrumented) } \\
\text { (Structures that } \\
\text { have similar } \\
\text { dimensions and } \\
\text { mass to that of } \\
\text { PWR fuel } \\
\text { assemblies and } \\
\text { simulate the } \\
\text { response of PWR } \\
\text { fuel assemblies to } \\
\text { S\&V forces) }\end{array}$ & $\begin{array}{l}\text { Much lower cost than surrogate fuel } \\
\text { assemblies that use spacer grids, } \\
\text { simulated fuel rods with cladding and } \\
\text { pellets, and representative fuel } \\
\text { assembly structure components. }\end{array}$ & $\begin{array}{l}\text { - Not surrogate fuel assemblies. } \\
\text { - Requires simulation analysis to inform and } \\
\text { revise design. }\end{array}$ \\
\hline
\end{tabular}




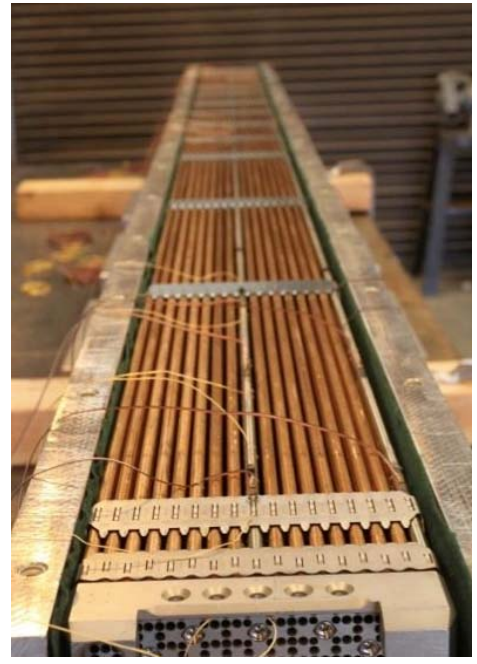

Figure 5-16. SNL Surrogate PWR Fuel Assembly

AREVA may also provide a surrogate PWR fuel assembly or assemblies that will also be instrumented for the Rail S\&V Test Program. It is likely the surrogate fuel assemblies provided by AREVA will represent state-of-the-art 17X17 design configurations used in the North Anna nuclear power reactors. As part of the overall program, AREVA has proposed to use its Lynchburg, Virginia Research Facility shaker-table to conduct shock and vibration tests on the fuel assemblies it would instrument and place into instrumented sections of a TN-32 cask's basket. These tests would be coordinated with the rail operational tests to be conducted at TCRY in Richland, Washington. The shaker-table tests would also use shock and vibration power spectral density function inputs that would be developed in computer simulations performed at PNNL.

AREVA may also provide un-instrumented fuel assembly surrogates that would be placed in uninstrumented fuel basket locations in the TN-32 cask if the cask is used in the test program. Using surrogates in the un-instrumented locations in the TN-32 cask's basket will ensure that the basket's response to the shock and vibration forces is representative of that for a fully loaded cask.

\subsection{Approach for Creating Normal Rail Transportation Shock and Vibration Conditions}

This section identifies and describes some of the rail transportation characteristics that result in shock and vibration forces. The following discussion is not meant to be exhaustive, but provides perspective on the types of rail transportation features that would provide shock and vibration loads to a fuel assembly. The intent is to identify some of the conditions that will present bounding force inputs and that can be safely established on test track operated by TCRY. The full suite of tests to be conducted will be developed in the rail shock and vibration testing detailed test plan to be developed as part of FY 2015 work scope. 


\subsubsection{Potential Rail Test Environment Options}

Multiple track and rail car configurations exist that could contribute to shock and vibration forces on UNF assemblies during normal rail transport. The testing environment can be broken into conditions that would cause discrete shocks, and/or conditions that would cause repetitive (or cyclical) shocks/motion.

Rail frogs (Figure 5-17) are an example of rail track features that cause discrete shocks that are transmitted into railcar structures and payloads. Frogs are used at switched and level crossings, where a gap in a rail is necessary to facilitate a train passing from one set of rails to another. As a train passes over a frog it will generate an impact load on the railcar structure and payload that is proportional to the speed the train is traveling. Previous experimental work has shown that rail frogs cause occasional high-level shock pulses when compared to normal background shock and vibration during rail transport (Maheras et al. 2013).

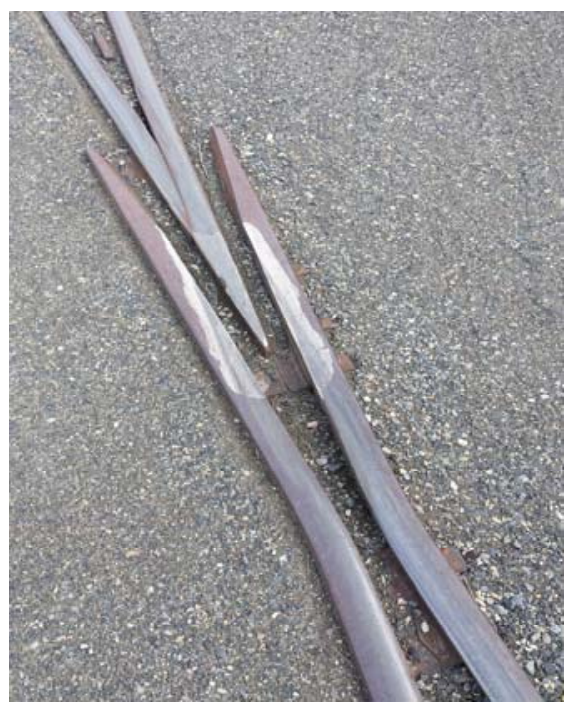

Figure 5-17. Rail Frog

Another example of discrete shock is the large impact load that can be imparted to a railcar and its payload when train cars are coupled. The severity of these coupling loads can vary depending on the speed at which a car is coupled, the type of draft gear used, and the mass of the railcar and its payload. A specific case where large impact loads can be seen because of car coupling occurs when cars are humped during rail yard operations (Figure 5-18). Typically the transport of UNF would be excluded from general freight, and thus would be excluded from humping in rail yard operations. However, simulated rail yard humping by coupling cars at similar speeds to those that would be seen at a hump yard would provide a good upper bound on shock loads from rail car coupling. 


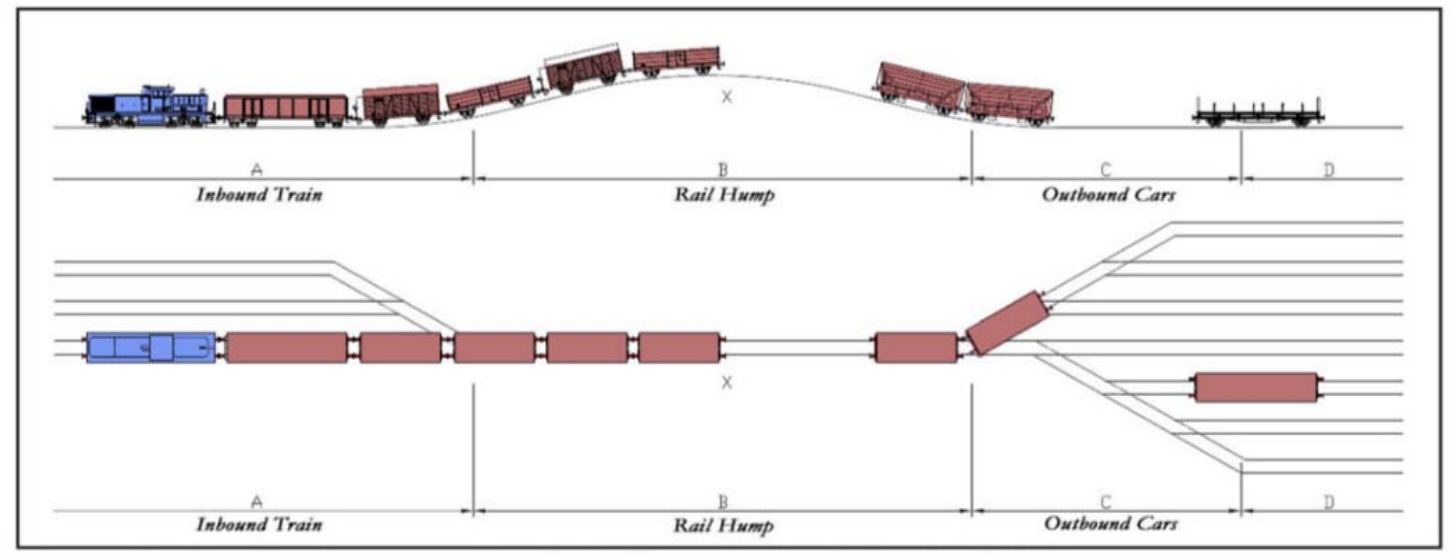

Diagram showing rail yard hump operation. Original image courtesy of Christian Lindecke.

Figure 5-18. Rail Yard Hump Operation (included with permission from Christian Lindecke)

Several types of squat, dipped, and other defects exist on the railhead and/or at track joints that also cause discrete shock impacts to a railcar's structure and payload. The most common are squat defects (Figure 5-19), which result from wheel impacts on the railhead, and dipped joints which most typically occur at bolted joints where a slight misalignment of the joint interface degrades overtime until a dip forms (Iwnicki, et al. 2006). Squat defects further deteriorate until a dip in the railhead forms. These two types of defects also generate impact loads that are proportional to the speed the train is traveling.

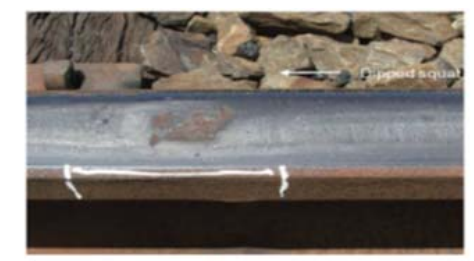

(a) $\# 1$ Squat defect

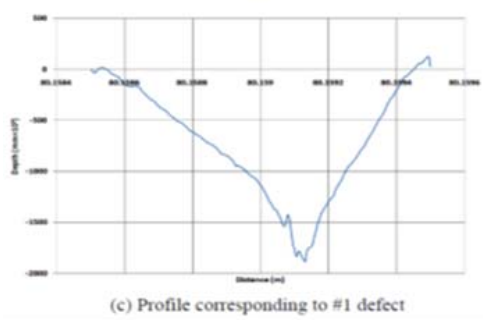

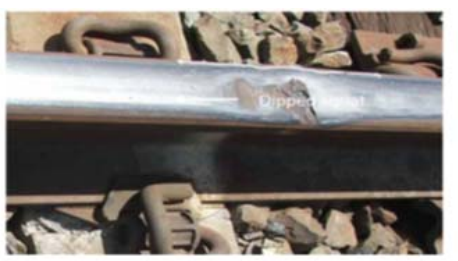

(b) 12 Squat defect

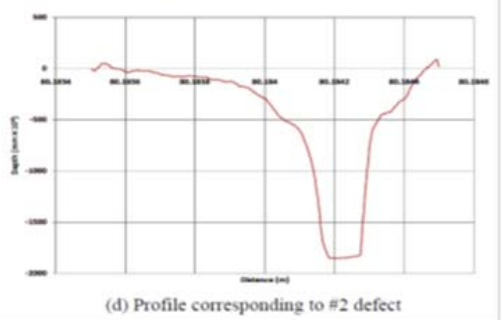

Figure 5-19. Squat Defects (With kind permission from Springer Science+Business Media: Journal of Mechanical Science and Technology, "Study on track dynamic forces due to rail short-wavelength dip defects using rail vehicle-track dynamics simulations," Volume 27, 2013, pp 629-640, YQ Sun, C Cole, and M Spiryagin, Figure 2.)

An example that would cause repetitive shocks/motion is wheel flats. Wheel flats are typically caused by low wheel-rail adhesion, which causes a wheel to slide across a rail for a short period. This action wears a flat into the wheel tread. Upon every subsequent revolution the wheel flat will produce an impact load that is transmitted into the railcar structure (Iwnicki et al. 2006). For 
example, Figure 5-20 shows that a train with relatively small wheel flats (40-mm length) can produce large wheel-rail contact forces.

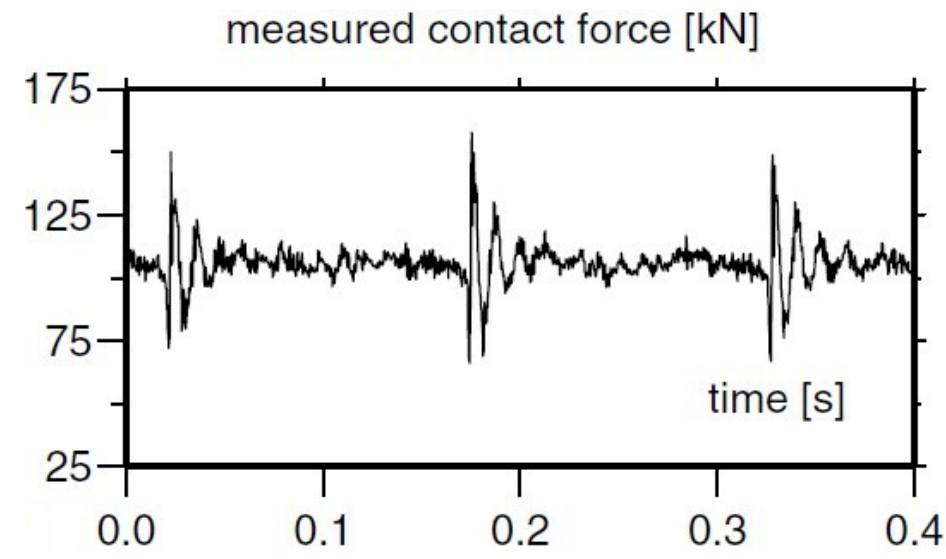

Figure 5-20. $40 \mathrm{~mm}$ Wheel Flats, Speed $70 \mathrm{~km} / \mathrm{h}$, and Axel Load 22 tons (Copyright 2006 from Handbook of Railway Vehicle Dynamics, S. Iwnicki, ed. Reproduced by permission of Taylor and Francis Group, LLC, a division of Informa plc.)

Corrugated rail (Figure 5-21) also is a source of repetitive shock/motion via a cyclic wear pattern that occurs on the surface of rails. It can be either short or long pitch, and will increase the dynamic wheel load and vibrations. The development of corrugation on the railhead is caused by the dynamics of the system, and linked to resonance effects. Most typically railhead irregularities with a wavelength ranging from $30 \mathrm{~mm}$ to $300 \mathrm{~mm}$ are known as rail corrugation. Under certain condition rail corrugation can lead to "fierce vibration of the vehicle and track" (Jin et al. 2005), and "corrugation generates high frequency vibration of the rail and wheel” (Iwnicki, et al. 2006)
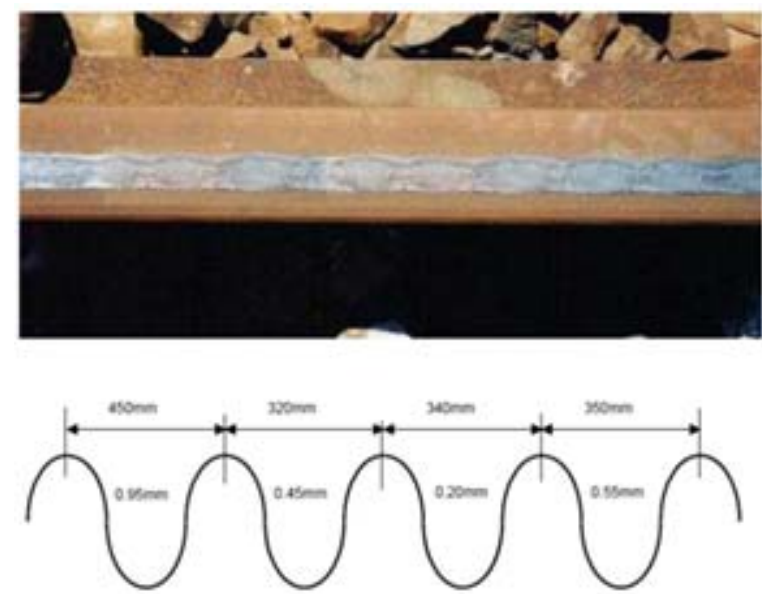

Figure 5-21. Corrugated Rail (Australian Rail Track Corporation, Ltd. 2006)

Various defects in track alignment, level, gauge, and/or cant can excite a rail vehicle (Figure 5-22). Long-wavelength geometric irregularities in track alignment will induce lateral displacements. Short-wavelength irregularities in track alignment and short-wavelength irregularities of the track level (i.e., vertical profile) will induce vibrations and noise. Irregularities in the track gauge will also induce lateral displacement of the car. Deficient, 
excessive, and/or changes in cant over a short distance can induce rolling, pitching, and yawing motion in a railcar (Iwnicki et al. 2006).

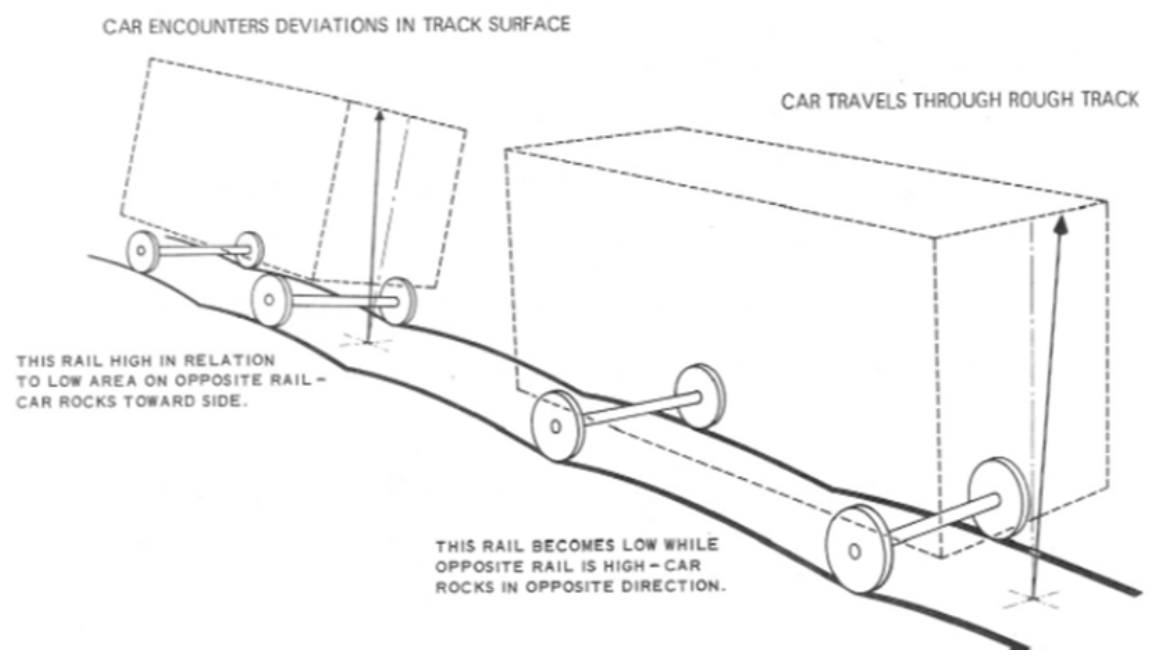

Figure 5-22. Railcar Instability Because of Differences in Track Cant (reprinted with permission from the author, Shust 2007),

A type of dynamic force generated between rail vehicles is slack action-the motion between cars that produces coupler forces during train movements. The effect is often magnified depending on the length of the train and the types of coupler used. Most draft gear allows for some free motion, and also allows for some controlled motion, which is intended to limit coupler forces. The rate at which slack action occurs is a function of the braking and tractive effort of the locomotive, braking by the rail vehicles, initial speeds of the rail vehicles, coupler clearances, and grade (Loumiet and Jungbauer 2005). Coupler forces because of slack action would most likely occur numerous times during transport; however, these coupler forces are generally most severe in very long trains.

Hunting is dynamic instability in the wheel set resulting in lateral oscillation as the wheel set "hunts" for a stable position on the rail. Hunting oscillation is the sustained lateral swaying of the railcar (Figure 5-23), and is inherent to most wheel sets because of the conical profile of the wheel (Iwnicki et al. 2006). Hunting is not a distinct rail feature, and would most likely be difficult to replicate during testing. However it is still important to note because railcar hunting is often unpredictable and results in violent excitation of the railcar.

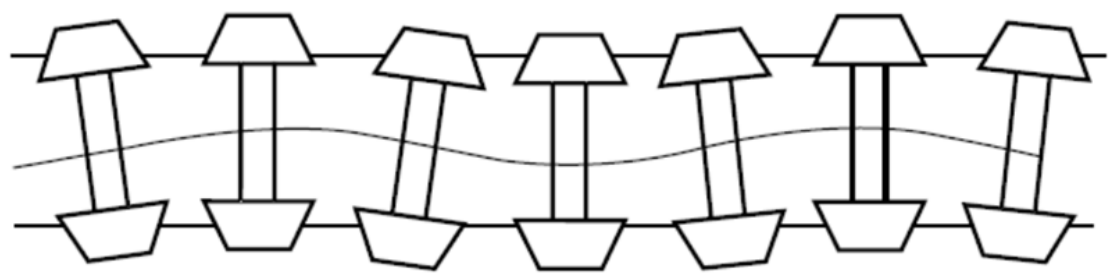

Figure 5-23. Hunting Oscillation (Copyright 2006 from Handbook of Railway Vehicle Dynamics, S. Iwnicki, ed. Reproduced by permission of Taylor and Francis Group, LLC, a division of Informa plc.) 
Other options for rail shock and vibration testing will be evaluated for inclusion in the rail shock and vibration test plan. Their inclusion will depend upon the ability to duplicate the condition reliably in a controlled environment and the potential for the phenomena to be encountered during normal rail transportation. An example of other options would be measuring the response generated at different speeds (e.g., ranging from $10 \mathrm{mph}$ to $65 \mathrm{mph}$ in 5-mph increments), and/or a combination of the features listed above.

\subsection{Approach for Computer Simulations and Analyses}

The modeling is a critical piece of the test series, and will draw on established numerical models where practical. TTCI's NUCARS railcar modeling software (Blader and Klauser 1989) is an established railcar model with a long history of use. The analytical models and results of the Modsim Report (Adkins et al. 2013b) are available. The modeling will leverage the prior work to focus on the phenomena that were not yet accounted for in the determination of loads and explore sensitivities the Modsim Report identified but did not evaluate. The end goal is to establish a complete understanding of the loads transmitted to the fuel during NCT, document the characteristics of the conveyance test system, and define a validated modelling methodology that effectively connects the railroad track to the fuel. The details of this process remain to be developed. The following subsections discuss some of the necessary modeling components.

The initial assessment of the test options has revealed a strong dependence on the configuration of the cask and cradle structure. The models used in the assessment would be best described as a first cut at understanding the dynamic response. Issues like mesh sensitivity that would normally be explored in finite element analysis have not been considered, and should be before final judgments are made. The difference between the concrete block monolith and realistic cask/cradle system seems to be large enough that even though the models have not been fully vetted, a concrete block does not look to be acceptable for the purposes of testing.

\subsubsection{Preliminary Modeling of Cask/Cradle}

It is recommended that the first modeling task be studying the dynamic response of additional cask and cradle designs to determine their dynamic response properties. Modal analysis and frequency response analysis would be used to characterize a number of cask and cradle designs. This preliminary work would help guide the selection of a candidate cask/cradle system or design a mock-up system that can accommodate the full range of dynamic response.

This type of modelling is needed to inform the choice of test options and to characterize the range of cask/cradle designs in existence. The cask/cradle system illustrated in Cummings, et al. (2012) can be approximated in a numerical model as one candidate. The existing approximate TN-32 cask and saddle model requires some refinement and further study. The INL 10/24 cask/cradle system is expected to be located at TCRY in the near future, so offers an actual cask/cradle system to measure and test. Additional cask/cradle systems can be evaluated if information becomes available. 


\subsubsection{Pre-test Simulations for Stationary Tests}

A number of tests are desired prior to running the test system on the railroad track. An initial set of stationary tests are planned to ensure the data acquisition system and transducers are collecting realistic data. In this context, stationary means the tests will be conducted inside the TCRY shop facilities. The stationary tests are dynamic in nature, and include impulse-type loading using the overhead crane at the TCRY facilities and a coupling load. These types of tests will generate data to be used to validate the cask and cradle characterization discussed in Section 4.3.1. The number of stationary tests will depend on the level of funding and choice of test option, but in general they are expected to include:

- Vertical Drop Load. The crane at TCRY can be used to drop a heavy object onto the railcar to deliver an impulse load that should excite the vibration modes of the railcar system. It may be possible to simulate loading the cask into the cradle supports, which is expected to cause a minor jarring of the system that would be picked up by the accelerometers.

- Coupling Load. Coupling is expected to cause a mechanical shock to the system of a magnitude that would cause no structural damage to the system but would be perceptible to the accelerometers. Coupling velocities could be increased to increase the magnitude of mechanical shock and provide insight into the dynamic behavior of the system as a whole.

- Lateral Impact Load. The crane at TCRY could be used to apply a lateral impact load against the system. Impacting the side of a cask with something like a railroad tie should be able to cause non-damaging impact loads to excite lateral vibration modes of the cask and cradle system.

The models would include the railcar, cradle, cask, and fuel assembly in high detail. It is recommended that TTCI's NUCARS railcar modeling software (Blader and Klauser 1989) be leased to gain access to their existing library of railcars. The numerical NUCARS model and model parameters could be translated into LS-DYNA (Livermore Software Technology Corporation 2007) format and used directly in this level of modeling. Using NUCARS models gives the advantage of using an established numerical model for the railcar, and allows the models of the cask and cradle to be compatible with any given railcar model in the NUCARS database.

\subsubsection{Post-Test Simulations}

The stationary tests offer some opportunity for pre-test predictions, but post-test evaluation of the models will provide valuable insight into fine tuning the models. Accelerometer data will capture the specific load response and the numerical models can be specifically loaded to match the actual test conditions.

The over-the-rail testing is not conducive to pretest predictions because the loads on the system or the fuel assembly will remain unknown until the test is performed. After over-the-rail testing, the accelerometer data will supply enough information to attempt to replicate specific sections of the shock and vibration load. 


\subsubsection{Shaker Test Modeling}

If shaker testing is performed, models can be constructed to perform pre- or post-test simulations. Pre-test simulations allow for predicting the cladding response. Post-test simulations are needed if the actual shaker loads deviate from the intended shaker loads. The testing offers validation for the models.

\subsection{Test Instrumentation Approach and Methods}

The shock and vibration testing instrumentation will be used to characterize the shock and vibration experienced during the transportation testing of a surrogate fuel assembly in a rail cask on a railcar. The input frequencies, amplitude, and locations will be correlated to cask structural response and will be used as input to the finite element analysis models.

It is expected that a number of accelerometers and strain gauges will be placed on the cask, the surrogate fuel assembly and on the railcar. The specific number and locations of the instrumentation will be determined when a shock and vibration testing option is chosen. The intention would be to measure rail transportation field measurements of normal vibration, transients, and potential railcar coupling events.

The placement of instrumentation will be guided by some preliminary structural analysis. The total number of instruments and number of data channels should be determined based on modeling to determine the major structural load paths into the cask and surrogate fuel assembly system. The data collection system will be pretested to verify that accelerometers are recording amplitudes correctly and to test instrumentation to verify that data logging is taking place prior to initiation of actual test.

The instrumentation selection and placement will be discussed in detail as part of the rail shock and vibration test plan to be developed as part of FY 2015 activities. 


\section{SUMMARY OF OPTIONS}

This report presented options for analyzing shock and vibration loads on a surrogate fuel assembly shipped by rail. The configurations proposed are based on the potential availability of the casks and other equipment described in the options. The ultimate selection of an option will begin with the selection of a cask system. As a result of the cask selection some of the other options will be determined based on what can support the selected cask. Tables 6-1 through 6-4 presents a summary of the disadvantages and advantages of the proposed options. Also, the evaluation of the computer modeling efforts indicated:

- Modeling is a critical component of this test campaign.

- The design of the cask/cradle system influences the loads transmitted to the fuel.

- Whatever option is chosen for the test campaign, cradle design modeling and characterization must be performed to document the test configuration so the results can be viewed in context.

Another element of the rail shock and vibration testing that has not been addressed in this report is the cost. As decisions are made in FY 2015 about the options for rail shock and vibration testing, detailed cost estimates will be developed for the option(s) chosen. 
Table 6-1. Summary of Option 1, TN-32 (Tri-City Railroad)

Option 1 Highlights

- S\&V testing in a controlled environment with a TN-32 "sister" cask at the TCRY facilities in Richland, Washington

- $\quad$ SNL and AREVA assemblies

- Flat deck railcar or depressed-center railcar

- Potential for cross-county travel S\&V data collection

\begin{tabular}{|l|l|}
\hline \multicolumn{1}{|c|}{ Advantages } & \multicolumn{1}{c|}{ Disadvantages } \\
\hline Technical & Technical
\end{tabular}

- $\quad$ TCRY testing capability, flexibility, access, and convenience

- $\quad$ TN-32 is modern storage cask

- AREVA-designed transport cradle and basket

- Flexibility in railcar selection

- Controlled test environment correlates to finite element modeling

- TCRY access to revenue track, if desired

- Cross-country trip representative of routing for UNF shipments

- Modeling used to simulate impact limiters

- $\quad \mathrm{S} \& \mathrm{~V}$ data collected for long distance traveled lack a controlled environment, which makes correlation to finite element modeling difficult.

- Data collection system chance for failure en route Cost

- $\quad$ Lease or purchase TN-32 cask

- Cost for use of basket or for AREVA to fabricate basket and cradle

- Cost of cross-country transport from York, Pennsylvania to Richland, Washington

- Cost, viability, and access to instrumentation and data collection system and monitoring for potential cross-country data collection (if used)

- Cost and complexity to provide special cask lid or other arrangements to allow fuel assembly and basket instrumentation to pass through to outside of cask

HBU = high burnup, PNNL = Pacific Northwest National Laboratory, S\&V = shock and vibration, SNL = Sandia National Laboratories, TCRY $=$ Tri-City Railroad, UNF $=$ used nuclear fuel 
Table 6-2. Summary of Option 2, TN-32 (Dominion)

\section{Option 2 Highlights}

- S\&V testing with a TN-32 cask in transit from Precision Components Corporation Facility (York, Pennsylvania) to Columbiana High Tech in Greensboro, North Carolina

- $\quad$ SNL and AREVA assemblies

- $\quad$ Flat deck railcar or depressed-center railcar

\begin{tabular}{|c|l|}
\hline \multicolumn{1}{|c|}{ Advantages } & \multicolumn{1}{c}{ Disadvantages } \\
\hline Technical & Technical
\end{tabular}

- $\quad$ TN-32 cask is a modern storage/transport cask that will be used to transport HBU fuel following the dry storage tests at the North Anna nuclear power plant

- Cost of TN-32 cask paid for by Dry Storage Demonstration Project

- AREVA instrumented 17X17 surrogate assemblies (for North Anna fuel assemblies)

- Collaboration with industry and utilities

- Fabrication of basket and cradle by AREVA

- $\mathrm{S} \& V$ data collected during long-distance commercial rail transport

- Acquisition of railcar by AREVA

- Cost

- Cost of proposed rail trip from Pennsylvania to North Carolina paid for by Dry Storage Demonstration Project
- Logistics, complexity, and time required to set up and coordinate the scope and details of testing before, and not to interfere with, start of the Dominion dry storage demonstration tests

- Modeling used to simulate impact limiters

- $\mathrm{S} \& \mathrm{~V}$ data collected for long distance traveled lack a controlled environment, which makes correlation to finite element modeling difficult.

- Data collection system chance for failure en route

- Sources of S\&V forces occurring en route not practically verifiable

- Limited rail travel not representative of routing for UNF shipment

- $\mathrm{S} \& \mathrm{~V}$ input forces for rail route traveled cannot be determined to be representative of the range of forces that would occur for travel on all routes that could be used to ship HBU UNF unless extensive rail travel is undertaken

- Potential that it will not be possible to instrument basket that will be used in North Anna dry storage tests

- Less flexibility in selection of railcar

Cost

- Cost for use of basket or for AREVA to fabricate basket and cradle

- Complexity of instrumenting fuel assemblies inside cask without special closure lid or cost of special lid arrangement

HBU = high burnup, S\&V = shock and vibration, SNL = Sandia National Laboratories, UNF = used nuclear fuel 
Table 6-3. Summary of Option 3, NLI 10/24

\section{Option 3 Highlights}

- S\&V testing in a controlled environment with a NLI-10/24 cask at TCRY facility in Richland, Washington

- Potential for data collection cross country from Augusta, Georgia to TCRY in Richland, Washington

- $\quad$ SNL and AREVA assemblies

- $\quad$ NLIX flat deck railcar

- Potential for cross-county travel S\&V data collection with basket and surrogate assemblies

\begin{tabular}{|l|l|}
\hline \multicolumn{1}{|c|}{ Advantages } & \multicolumn{1}{c|}{ Disadvantages } \\
\hline Technical & Technical
\end{tabular}

- TCRY owns the NLI cask and railcar, which will be domiciled at the TCRY Richland, Washington facility.

- Ability to perform controlled repeatable experiments over known track conditions at TCRY to better inform modeling

- $\quad$ NLIX railcar specifically designed for the NLI cask

- $\quad$ NLI cask is a previously certified 100-ton UNF rail transportation cask

- Controlled test environment correlates to finite element modeling

- TCRY access to revenue track, if desired

- Cross-country trip representative of routing for UNF shipments

\section{Cost}

- Lease cask and railcar

- TCRY facility capability, flexibility, access, and convenience
- $\quad \mathrm{S} \& \mathrm{~V}$ data collected for long distance traveled lack a controlled environment, which makes correlation to finite element modeling difficult.

- Data collection system chance for failure en route

- Sources of S\&V forces occurring en route not practically verifiable

- Limited rail travel not representative of routing for UNF shipment

- Not a modern rail cask

Cost

- Fabrication of basket and instrumentation lid

- Age and condition of NLIX railcar may require refurbishment of NLIX railcar or acquisition (lease) of alternative railcar and procurement of transport cradle for cask

S\&V = shock and vibration, SNL = Sandia National Laboratories, TCRY = Tri-City Railroad, UNF = used nuclear fuel 
Table 6-4. Summary of Option 4, Engineered Mass on a Railcar

Option 4 Highlights

- S\&V testing in a controlled environment with a engineered mass on a railcar at TCRY facility in Richland, Washington

- $\quad$ SNL and AREVA assemblies

- Flat deck railcar or depressed center railcar

- Potential for cross-county travel S\&V data collection with basket and surrogate assemblies

\begin{tabular}{|l|l|}
\hline \multicolumn{1}{|c|}{ Advantages } & \multicolumn{1}{c|}{ Disadvantages } \\
\hline Technical & Technical
\end{tabular}

- Flexibility in fabrication of mass to simulate size and weight of modern UNF transport casks

- Provides option to vary cask and test features in conducting rail test operations and collecting S\&V test data from surrogate components for comparison to results of computer-based simulations

- Provides ease of access to fuel assemblies for instrumentation

- Controlled test environment correlates to finite element modeling

- TCRY access to revenue track, if desired

- Cross-country trip representative of routing for UNF shipments

\section{Cost}

- Significantly reduced cost for simulated cask fabricated at TCRY, compared to cost to obtain use of a modern UNF rail cask transported to TCRY

- Optics of mass on a railcar (fabricated mass will not be a UNF transportation cask).

- Uncertainties will be introduced by the simulation into test results.

- $\quad \mathrm{S} \& V$ data collected for long distance traveled lacks a controlled environment which makes correlation to finite element modeling difficult.

- Data collection system chance for failure en route

- Sources of S\&V forces occurring en route not practically verifiable

- Limited rail travel not representative of routing for UNF shipment

\section{Cost}

- Cost to design (including simulation analysis to verify that the surrogate mass characteristics are representative) and fabricate surrogate mass, surrogate basket, and cask cradle that model rail cask behavior

S\&V = shock and vibration, SNL = Sandia National Laboratories, TCRY = Tri-City Railroad, $\mathrm{UNF}=$ used nuclear fuel 


\section{REFERENCES}

AAR (Association of American Railroads). 2008. "Performance Specification for Trains Used to Carry High-Level Radioactive Material.” Standard S-2043, AAR Manual of Standards and Recommended Practices, Section C, Car Construction Fundamentals and Details. Association of American Railroads, Washington, D.C. Amended by AAR Circular Letter C-10914, December 18, 2008; AAR Circular Letter C-11084, August 18, 2009; and AAR Circular Letter C-11113, October 23, 2009.

Adkins HE et al. 2013a. "Used Nuclear Fuel Loading and Structural Performance Under Normal Conditions of Transport - Method and Approach.” FCRD-TIO-2011-00050. U.S. Department of Energy, Washington D.C.

Adkins HE, KJ Geelhood, BJ Koeppel, J Coleman, J Bignell ,G Flores, J Wang, SE Sanborn, R Spears, NA Klymyshyn. 2013b. "Used Nuclear Fuel Loading and Structural Performance Under Normal Conditions of Transport - Demonstration of Approach and Results on Used Fuel Performance Characterization,” FCRD-UFD-2013-000325, Pacific Northwest National Laboratory, Richland, WA

Australian Rail Track Corporation, Ltd. 2006. Rail Defects Handbook. Issue A, Revision 0, RC 2400. Available at http://extranet.artc.com.au/docs/eng/track-civil/guidelines/rail/RC2400.pdf.

Blader FB and PE Klauser. 1989. User's Manual for NUCARS Version 1.0, Report R-734, Association of American Railroads, Chicago, Illinois.

Cummings AD, J Krywonos, P Purcell, G Rothwell, and R English. 2012. “An Experimental Procedure for Measuring Accelerations and Strains from a Tie Down System of a Heavy Nuclear Transport Package During a Rail Journey.” Transport, Storage, and Security of Radioactive Material, 23(3/4):167-177.

Gurule, ST and WC Shust. 2005. Preliminary NUCARS Evaluation of Viable Truck Types Using 0.5 for Rail Friction. Transportation Technology Center, Inc. (TTCI), Pueblo, Colorado.

Iwnicki S (ed). 2006. Handbook of Railway Vehicle Dynamics. CRC Press, Boca Raton, Florida.

Jin X, Z Wen, K Wang, and W Zhang. 2005. "Effect of rail corrugation on vertical dynamics of railway vehicle coupled with a track.” Acta Mechanica Sinica 21(1):95-102.

Klymyshyn N, S Sanborn, H Adkins, and B Hanson. 2013a. Fuel Assembly Shaker Test Simulation. FCRD-UFD-2013-000168, PNNL- 22507, Pacific Northwest National Laboratory for the U.S. Department of Energy, Washington D.C.

Klymyshyn N, N Karri, H Adkins, and B Hanson. 2013b. Structural Sensitivity of Dry Storage Canisters. FCRD-UFD-2013-000378, PNNL-22814, Pacific Northwest National Laboratory for the U.S. Department of Energy, Washington D.C.

Livermore Software Technology Corporation. 2007. LS-DYNA Keyword User's Manual, Volume 1, Version 971, Livermore Software Technology Corporation. 
Loumiet JR and WG Jungbauer. 2005. Train Accident Reconstruction and FELA and Railroad Litigation. Fourth Edition, Lawyers \& Judges Publishing Company, Inc., Tucson, Arizona.

Maheras SJ, EA Lahti, and SB Ross. 2013. Transportation Shock and Vibration Literature Review. PNNL-22514, FCRD-UFD-2013-000169, Pacific Northwest National Laboratory for the U.S. Department of Energy, Washington D.C.

McConnell P, G Flores, R Wauneka, G Koenig, D Ammerman, J Bignell, S Saltzstein, and K Sorenson. 2013. Fuel Assembly Shaker Test for Determining Loads on a PWR Assembly under Surrogate Normal Conditions of Truck Transport. SAND2013-5210P, Rev 0.1, FCRD-UFD2013-00190, Sandia National Laboratories for the U.S. Department of Energy, Washington D.C.

McConnell P, et al. 2014. Normal Conditions of Transport Truck Test of a Surrogate Fuel Assembly., FCRD-UFD-2014-000066, Sandia National Laboratories for the U.S. Department of Energy, Washington D.C.

Shust, WC. 2007. “Shock and Vibration in Rail and other Transport Modes” 2007, Objective Engineers, Inc. Available at http://railtec.illinois.edu/CEE/pdf/PPT's/previousppts/univ_illinois_shust.pdf.

Sun YQ C Cole, and M Spiryagin.2013. "Study on track dynamic forces due to rail shortwavelength dip defects using rail vehicle-track dynamics simulations.” Journal of Mechanical Science and Technology 27(3):629-640. 